DIW BERLIN

Discussion

Papers
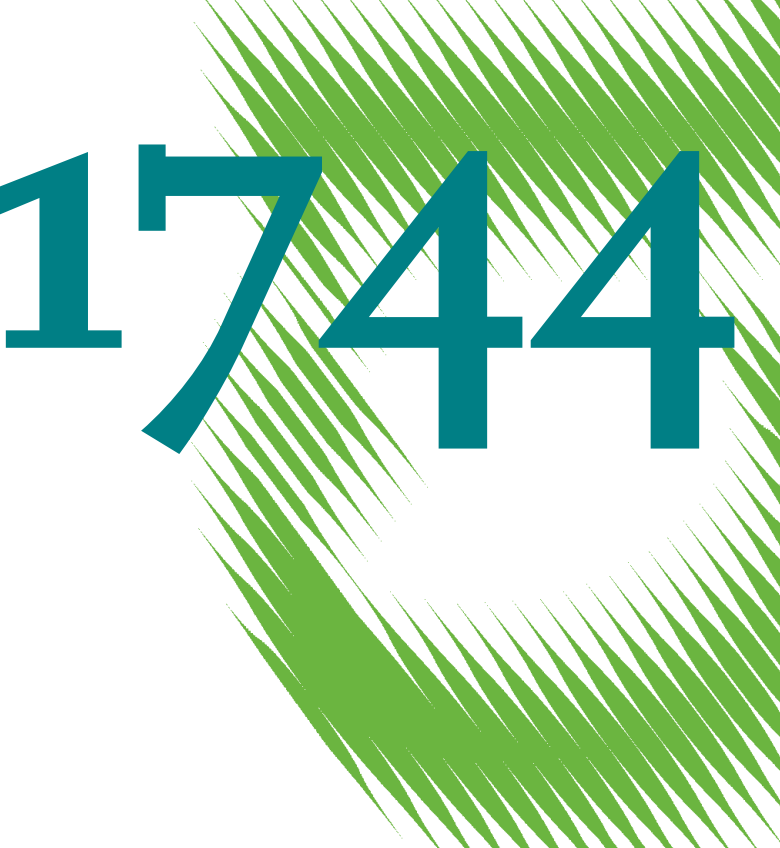

s.
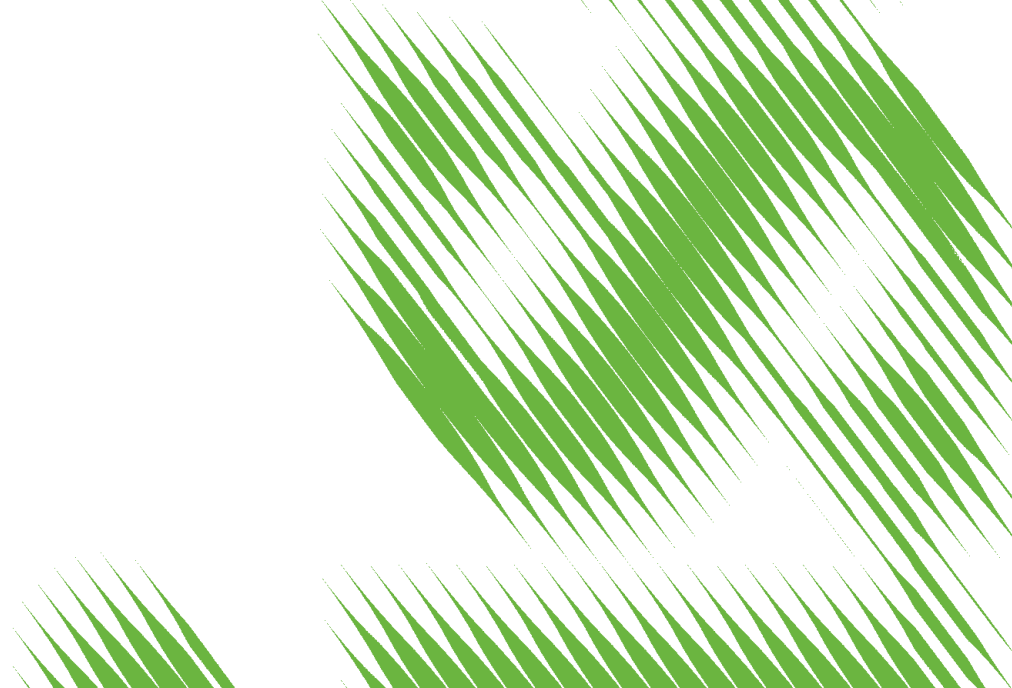

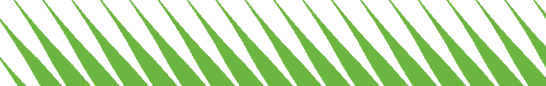

Herd Behavior in FDA Committees

A Structural Approach 
Opinions expressed in this paper are those of the author(s) and do not necessarily reflect views of the institute.

IMPRESSUM

(C) DIW Berlin, 2018

DIW Berlin

German Institute for Economic Research

Mohrenstr. 58

10117 Berlin

Tel. +49 (30) $89789-0$

Fax +49 (30) $89789-200$

http://www.diw.de

ISSN electronic edition 1619-4535

Papers can be downloaded free of charge from the DIW Berlin website:

http://www.diw.de/discussionpapers

Discussion Papers of DIW Berlin are indexed in RePEc and SSRN:

http://ideas.repec.org/s/diw/diwwpp.html

http://www.ssrn.com/link/DIW-Berlin-German-Inst-Econ-Res.html 


\title{
Herd Behavior in FDA Committees: A Structural Approach*
}

\author{
MELissa NEWHAM ${ }^{\dagger}$ \\ Rune MidjorD ${ }^{\ddagger}$
}

June 2018

\begin{abstract}
Many important decisions within public and private organizations are based on recommendations from expert committees and advisory boards. A notable example is the U.S. Food and Drug Administration's advisory committees, which make recommendations on new drug applications. Previously the voting procedure for these committees was sequential, however, due to concerns of herding and momentum effects the procedure was changed to simultaneous voting. Exploiting a novel dataset of more than ten thousand votes cast by experts in the FDA committees under both sequential and simultaneous voting, we estimate a structural model that allows us to measure the magnitude and importance of informational herding. We show that experts, voting on important scientific questions, are susceptible to herd behavior; on average $46 \%$ of the members take into consideration the sequence of previous votes when casting their vote, $17 \%$ of these voters actually herd i.e. change their vote from what they would have voted if ignoring the preceding votes.
\end{abstract}

JEL-codes: D72, D82, D83, D91, I10, I18

Key words: Herd behavior, expert committees, structural estimation, FDA, pharmaceuticals

*All co-authors contributed equally to this paper. We thank Kai Barron, Nuria Boot, Steven Durlauf, Tomaso Duso, Nicolas de Roos, Jo Seldeslachts, Peter Sørensen, Timothy Simcoe, Hannes Ullrich and Georg Weizsäcker for helpful comments. We further thank seminar participants at DIW Berlin for valuable comments and suggestions.

${ }^{\dagger}$ KU Leuven and DIW Berlin (e-mail: melissa.newham@kuleuven.be)

${ }_{\ddagger}$ Copenhagen Business School (e-mail: rm.ino@cbs.dk) 
"CHAIRMAN ABRAMSON: What I'd like to do is now go to question number 4 and take a vote as to whether the committee concurs that there is adequate evidence to approve rofecoxib as an analgesic. . . . Let's go around this way. Dr. Katona.

DR. KATONA: I was hoping I wouldn't be the first one for this difficult question." 1

\section{Introduction}

Many important decisions within public and private organizations are based on nonbinding recommendations from expert committees and advisory boards. Advisory boards composed of industry experts give strategic advice to the management of large corporations and expert committees are used in many countries to provide regulators with recommendations on issues such as health, climate, monetary policy, and military conflict. In order to gauge the collective information held by the individual committee members it is common to have a formal vote. A notable example is the U.S. Food and Drug Administration's advisory committees. In these committees, around a dozen of medical experts openly discuss and vote on issues related to the approvability of new drug applications. ${ }^{2}$ Until 2007 the voting procedure was sequential, however, due to concerns of herding and momentum effects (with references to Banerjee (1992) and Callander (2007)) the FDA changed the voting procedure to simultaneous (electronic) voting. ${ }^{3}$

In this paper, we develop a model of voting in advisory committees and estimate the model with voting data from the FDA's committees using more than ten thousand indi-

\footnotetext{
${ }^{1}$ Extract from FDA Advisory Committee meeting on new drug application Vioxx (rofecoxib), 20 March 1999. The roll call was a unanimous "yes" with one abstention (Dr. Katona).

${ }^{2}$ These committees are purely advisory. As explained by the clinical FDA team leader at the meeting of the approval of Olodaterol: "Before I close, I just wanted to mention the legal framework that gives the FDA the ability to hold advisory committees to ask for scientific advice and recommendations from experts in the field. As I noted previously, the FDA takes very seriously the advice of the committee. However, the Commissioner has sole discretion on actions taken with regard to drug approval, especially since there may be other issues, such as manufacturing, not discussed at the meeting, that impact approval decisions."

3 "There has been much discussion inside and outside FDA regarding sequential versus simultaneous voting...scholars and social scientists have studied the risk of "momentum" in sequential voting, exploring whether some sequential voters may be influenced, perhaps even subconsciously, by the votes that precede theirs, especially if those votes are nearly identical or signal a clear trend[footnote reference to Banerjee (1992) and Callander (2007)]." In Draft Guidance for FDA Advisory Committee Members and FDA Staff: Voting Procedures for Advisory Committee Meetings (2007).
} 
vidual votes from both sequential and simultaneous voting. The data is gathered from publicly available verbatim transcripts which gives us information on the exact sequence of votes under sequential polling. Despite the importance of expert committees in many economic situations, we are not aware of previous empirical papers studying whether, and to what extent, expert panelists are susceptible to herd behavior when asked for scientific advice. ${ }^{4} 5$ Moreover, our model and estimates allow us to study whether simultaneous voting improves information aggregation, thereby potentially leading to more informed drug approval decisions. Decisions which affect millions of users. If beneficial drugs do not win approval patients miss the opportunity of improved medication and if bad drugs are approved the consequences can be fatal. ${ }^{6}$

The formal analysis of herd behavior started with Banerjee (1992), Bikhchandani et al. (1992), and Welch (1992). In this setting, agents choose actions sequentially and are uncertain about the correct action, which depends on the state of the world. Agents receive imperfect private signals about the state and may infer additional information from observing the actions of the preceding agents. The latter effect can give rise to herds or cascades whereby, after a number of agents have chosen the same action, all following agents imitate their predecessor. ${ }^{7}$ Smith and Sørensen (2000) extend the classical setup by admitting heterogeneous preferences and continuous signals. In our model, agents receive continuous signals and we incorporate informative (expressive) types into the herding framework. Informative types stay true to their personal judgment and are never swayed by the history of actions.

More specifically, we consider advisory committees voting on independent yes/no questions. For example, whether the benefits of a new drug outweigh the risks. On each voting question, there is a common prior on the correct answer (the state) being

\footnotetext{
${ }^{4}$ Although not linked to herding, Meade (2005) study behaviors of the FOMC committee and show that Greenspan's proposals, after committee discussion, were nearly always adopted unmodified in the formal vote, though the rate of disagreement in internal committee discussions was quite high.

${ }^{5}$ Herd behavior and observational learning have been studied in many different empirical settings. To mention a few: presidential primaries (Knight and Schiff, 2010), restaurant dining (Cai et al., 2009), investment recommendations (Graham, 1999), stock market trading (Cipriani and Guarino, 2014), and movie reviews (Camara and Dupuis, 2014).

${ }^{6}$ One of the most debated FDA decisions is the approval of the painkiller Vioxx (nytimes.com/topic/subject/vioxx-drug). According to Graham et al. (2005) Vioxx caused an estimated 88.000 to 140.000 excess cases of serious heart disease in the U.S. over its market life.

${ }^{7}$ The game in Bikhchandani et al. (1992) has been studied extensively in controlled laboratory experiments, see Anderson and Holt (1997) for an early reference and Weizsäcker (2010) for a meta analysis. See Celen and Kariv (2004) for the case of continuous signals and discrete actions and Angrisini et al. (2017) for a social learning experiment with a continuous action space.
} 
"yes." The prior contains relevant public information on the question at hand including committee discussions and presentations leading up to the voting stage. On top of this, each expert receives a private and independent signal about the state. To this end, each panelist draws on his/her unique experience, intuition, and analytical skills. The signals are heterogeneous in the sense that some members may receive extreme signal realizations that (almost) reveal the state and others learn close to nothing. The general precision of the signals is the same across committee members and voting questions. Our signal structure is the same as in Cipriani and Guarino (2014) who estimate a structural model of herd behavior with financial transaction data.

There are two types of committee members in our model. The learning type uses the preceding votes and his/her private signal to update (Bayesian) beliefs about the state and then seeks to match his/her vote with the true state. The informative type automatically opts for the option which is more likely to be correct only taking his/her private signal into consideration. ${ }^{8}$ Types are private information and distributed independently across voters and voting questions. Herd voting occurs when a learning type votes yes (no) whereas had he/she not observed the vote history he/she would have voted no (yes). ${ }^{9}$ When voting is simultaneous the only premise that changes is that the vote-history is empty for all the committee members and thus learning types act as informative types and there is no herding.

Our structural approach and unique data, with numerous voting questions under both voting procedures and information on the exact voting sequence under sequential polling, allow us to pin down the proportion of learning types and separate the effect of herd voting from changes in the prior on the state and the accuracy of the committee members' private information. Whereas the prior on the state is identified by the proportion of yes votes at the vote question level, the precision of private information depends on the agreement of votes across different voting questions. To identify herding the sequence of votes under sequential voting is crucial. Intuitively, learning types tend to be more responsive to the most recent votes when considering the sequence of preceding votes.

\footnotetext{
${ }^{8}$ Our model is a model of statistical herding with informative types added. A closely related concept is reputational herding where agents are motivated by appearing to be well informed about the state i.e. having strong private signals (see Ottaviani and Sørensen (2001) for a model of reputational concerns in committees).

${ }^{9}$ This definition of herd voting is similar to herd-buying and herd-selling in Cipriani and Guarino (2014).
} 
We find that almost half of the FDA committee members are susceptible to herd behavior. On average $46 \%$ of the committee members are learning types i.e. they take into consideration the sequence of previous votes when casting their vote, $17 \%$ of these voters actually herd i.e. they change their vote from what it would have been if they had ignored the preceding votes. Thus, on average, almost $8 \%$ of all the sequential votes are herd votes. The estimate on the accuracy of the committee members private information is relatively high; given the state, private signals go in the wrong direction only $20 \%$ of the time. We exploit data on individual voter characteristics such as educational background and gender to study heterogeneity in herd behaviour. We find that regular committee members and consumer/patient representatives are less susceptible to herd behaviour. On the other hand, gender or whether or not a member has a $\mathrm{PhD}$ has little impact on the likelihood that a member is influenced by the vote history.

We next consider the consequences of herding on information aggregation i.e. the amount of information passing from the experts, through voting, to the FDA. To assess information aggregation we consider the discrepancy between the true state and the updated Bayesian beliefs about the state after all the committee members have voted. We find that simultaneous voting improves information aggregation. In particular, given the estimates of our model's parameters the simultaneous procedure slightly improves the aggregation of information compared to sequential voting, thus providing support for the FDA's switch to simultaneous polling. However, and perhaps surprisingly, there are examples, typically for small committees, where sequential voting performs marginally better. Based on our estimates, we see that once a committee of around 12 members is established, additional committee members contribute only marginally to the information aggregation. Finally, if we contemplate what would happen if the FDA were to approve drugs only when a simple majority of the committee members vote in favor, then simultaneous voting leads to more erroneous decisions if the prior on the state is sufficiently unbalanced (different from 0.5).

Voting data from the FDA's drug committees have been used previously to study the connection between voting behavior and industry ties (see discussion in Camara and Kyle (2016)). Unlike the present paper, these studies do not distinguish between the two different voting procedures. Lurie et al. (2006) find a weak relationship between committee members' votes for approval and financial ties. Ackerley et al. (2009) extend the FDA data used in Lurie et al. (2006) and show a tendency for committee members to vote against their financial interests. Cooper and Golec (2017) find that conflicts of 
interests are not significantly related to votes in FDA committees. Using reduced-form methods, Camara and Kyle (2016) find a small positive correlation between financial ties and the tendency to vote in favor of a drug. They investigate this further using a structural model to estimate each member's skill and bias associated with financial ties to a drug's sponsor or its competitors. Their results suggest that members with financial ties are more likely to vote in favor of both "good" and "bad" drugs. However, members with financial ties also have somewhat higher estimated ability, and hence are more favorable towards good drugs.

More broadly, our paper is related to the literature on committees and the optimal design of voting bodies (see Gerling et al. (2005) and Li and Suen (2009) for surveys and Gerardi and Yariv (2008) for a mechanism design approach). This literature mainly focuses on committees making binding decisions in a common value setting. In this context, studies regarding sequential versus simultaneous voting include Dekel and Piccione (2000) and Ali et al. (2008).

On a different note, our paper is related to studies on social conformity and sequential decision making, where individuals are influenced by observing others' actions, not because of information revealed about an underlying state, but due to mechanisms of social conformity. In a famous experiment by Asch (1951), seven confederates seated before a critical subject were instructed to give an incorrect answer to an easy task on visual perception. Around $32 \%$ of the answers from the critical subjects were the same as the erroneous majority. For discussions on the distinction between informational and social influence see Deutsch and Gerard (1955), Shiller (1995), and Bernheim and Exley (2015).

The rest of the paper is organized as follows. Section 2 introduces the theoretical model. Section 3 describes the data and Section 4 undertakes a descriptive and reducedform (regression) analysis of the data. Section 5 describes the estimation procedure. Section 6 discusses the main results. Section 7 extends the model to incorporate heterogeneity in herd behavior across voters and Section 8 considers information aggregation. Section 9 concludes. 


\section{Model}

We consider advisory committees voting on various yes/no questions. As in the case of the FDA's advisory committees, we can think of expert panelists polling on complex matters regarding a specific application or scientific question. There are $J$ voting questions and a generic voting question is denoted by $j \in\{1, \ldots, J\}$. The number of voting members on question $j$ is $N^{j} \geq 2$. For each voting question, $j$, there is a common unobserved state $\theta^{j} \in\{0,1\}$ that equals 1 if the correct answer to question $j$ is "yes" and 0 if the correct answer is "no." For example, if the committee votes on whether to approve a new medical drug then $\theta=1$ if the clinical benefits of the drug outweigh the risks. The state is independently drawn across the $J$ voting questions. Let $\mu_{0}^{j} \in(0,1)$ indicate the common prior belief that the true state is 1 . On question $j$, we denote the vote from committee member $i^{j} \in\left\{1^{j}, \ldots, N^{j}\right\}$ by $v_{i}^{j} \in\{1,0\}$, where $v_{i}^{j}=1$ is a "yes" vote and $v_{i}^{j}=0$ is a "no" vote.

Voting procedure. The voting procedure on question $j$ can be either sequential or simultaneous. If voting on question $j$ is sequential, then the panelists vote sequentially and openly in an exogenously given order. The voting order is such that committee member $i^{j}$ votes as the $i$ 'th person (i.e. member $1^{j}$ votes first, then member $2^{j}$, etc.). Let $h_{i}^{j} \equiv v_{1}^{j}, \ldots, v_{i-1}^{j}$ denote the voting history observable for member $i^{j}$ where $h_{1}^{j}=\{\emptyset\}$. If voting is simultaneous then the vote-history is empty for all committee members. We indicate by $\xi^{j} \in\{$ simultaneous, sequential $\}$ the voting procedure for question $j$.

Signals. For every voting question $j$, each committee member $i^{j}$ receives a private signal about the state. The signals are i.i.d. conditional on the state. The private signal $S_{i}^{j}$ has the following linear state-contingent densities (following Cipriani and Guarino (2014)):

$$
\begin{aligned}
& f^{1}\left(s_{i}^{j} \mid \theta^{j}=1\right)=1+\tau\left(2 s_{i}^{j}-1\right) \\
& f^{0}\left(s_{i}^{j} \mid \theta^{j}=0\right)=1-\tau\left(2 s_{i}^{j}-1\right)
\end{aligned}
$$

where $\tau \in(0, \infty)$. (See Figure 1.)

The parameter $\tau$ is a measure of the level of strength in the experts' signals, where a larger $\tau$ means better precision. Even for a large $\tau$ there may still be voting members who receive signal realizations close to one half, which adds little to their assessment of 
the state. In the case of the FDA's advisory committees, member $i^{j}$ 's signal realization can be thought of as a process whereby member $i^{j}$ considers the results and design of the clinical trials and draws on his/her personal experience, intuition, and analytical skills (also allowing for randomness and misconceptions) to arrive at some private signal realization.

When $\tau \leq 1$ the support of the densities is $[0,1]$. For $\tau>1$, the support shrinks to $\left[\frac{\tau-1}{2 \tau}, \frac{\tau-1+2 \sqrt{\tau}}{2 \tau}\right]$ for $f^{1}$ and $\left[\frac{\tau+1-2 \sqrt{\tau}}{2 \tau}, \frac{\tau+1}{2 \tau}\right]$ for $f^{0} \cdot{ }^{10}$ The signals satisfy the monotone likelihood ratio property. For committee member $i^{j}$, the likelihood ratio after receiving signal $s_{i}^{j}, \frac{\left.P\left(\theta^{j}=1\right) \mid h_{i}^{j}, s_{i}^{j}\right)}{\left.P\left(\theta^{j}=0\right) \mid h_{i}^{j}, s_{i}^{j}\right)}=\frac{f^{1}\left(s_{i}^{j} \mid \theta^{j}=1\right)}{f^{0}\left(s_{i}^{j} \mid \theta^{j}=0\right)} \frac{\left.P\left(\theta^{j}=1\right) \mid h_{i}^{j}\right)}{\left.P\left(\theta^{j}=0\right) \mid h_{i}^{j}\right)}$, is higher than the likelihood ratio before receiving the signal if $s_{i}^{j}>\frac{1}{2}$ and lower if $s_{i}^{j}<\frac{1}{2}$. In this way, a signal larger than one half is affirmative news and a signal lower than one half is negative news regarding the yes/no question at hand. As explained in Cipriani and Guarino (2014), when $\tau \geq 1$ there are some signal realizations, $s_{i}^{j}$, that are only possible when the state is 1 (or 0 ), which then reveal the true state with certainty to member $i^{j}$. In fact, when $\tau \geq 1$ signal realizations higher than or equal to $\frac{\tau+1}{2 \tau}$ are only possible when the state is 1 and signal realizations lower than or equal to $\frac{\tau-1}{2 \tau}$ are only possible when the state is 0 .

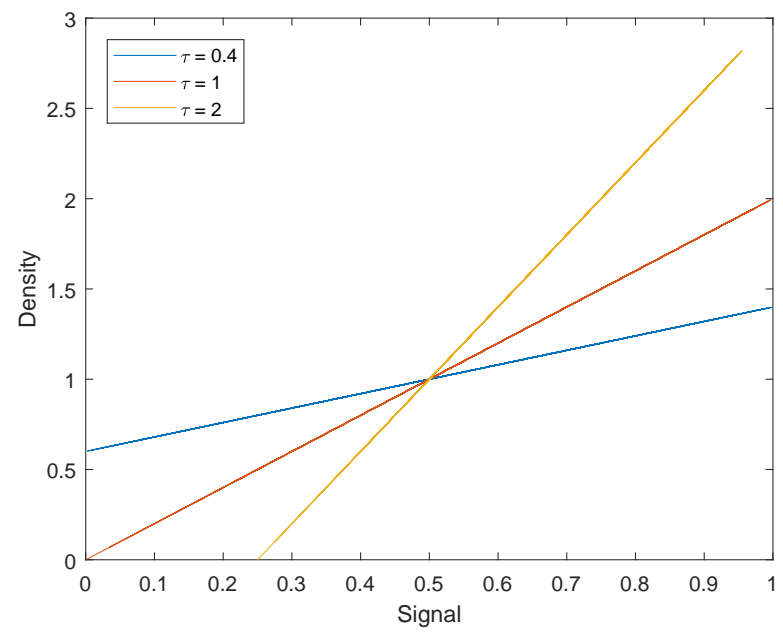

Figure 1: Probability Density Function of Private Signals $\mid \theta=1$

Types and payoffs. There are two types of voters: Informative type $(t=I)$ and learning type $(t=L)$. A member's type is private information. Types are distributed independently across voters and voting questions and the probability that a committee member is the learning type is $\lambda$. The informative type relies on his/her own signal

\footnotetext{
${ }^{10}$ The intervals ensure that the density functions integrate to one.
} 
and automatically votes for the option which is more likely to line up with the true state given his/her private signal. Such behavior could be warranted by an expressive payoff (see Brennan and Hamlin (1998)) and may stem from the informative type's desire, or direct value from, expressing his/her personal judgment on the voting question, reflected by his/her private signal realization. The learning type also strives to match his/her vote with the true state and in addition to the private signal he/she uses information from the vote-history to guide his/her vote. We assume that the learning type receives payoff 1 if $v_{i}^{j}=\theta^{j}$ and payoff 0 if $v_{i}^{j} \neq \theta^{j}$. In this way, type I and type II voting-errors weight equally. We can think of esteem as the main driver behind these payoffs (see Brennan and Pettit (2000) on the economics of esteem): When invited as expert on an advisory board, a panelist derives both self-esteem and repute from providing right answers to the voting questions.

We can formally characterize the voting behavior of member $i^{j}$ when he/she is the informative type. Let $\bar{s}_{i, t=I}^{j}$ indicate the cutoff signal such that $P\left(\theta^{j}=1 \mid \bar{s}_{i, t=I}^{j}\right)=1 / 2{ }^{11}$ Using Bayes' rule and the law of total probability:

$$
P\left(\theta^{j}=1 \mid \bar{s}_{i, t=I}^{j}\right)=1 / 2 \Longleftrightarrow \bar{s}_{i, t=I}^{j}=\frac{-2 \mu_{0}^{j}+\tau+1}{2 \tau}
$$

The cutoff signal from equation (1) characterizes the voting behavior of informative types: vote yes if $s_{i}^{j}>\bar{s}_{i, t=I}^{j}$ and vote no if $s_{i}^{j}<\bar{s}_{i, t=I}^{j}$. Note that (1) only applies when $\mu_{0}^{j} \in\left(\frac{1-\tau}{2}, \frac{1+\tau}{2}\right)$, which is not guaranteed if $\tau<1$. When $\mu_{0}^{j} \leq \frac{1-\tau}{2}$ it is optimal for member $i_{t=I}^{j}$ to vote no for any signal realization (i.e. when $\mu_{0}^{j} \leq \frac{1-\tau}{2}$ there is no possible signal realization such that $\left.\left.P\left(\theta^{j}=1 \mid s_{i}^{j}\right)>1 / 2\right)\right)$. Similarly, if $\mu_{0}^{j} \geq \frac{1+\tau}{2}$ then member $i_{t=I}^{j}$ votes yes for any possible signal realization.

The learning type uses the history of votes, in addition to his/her private signal, to update his/her beliefs about $\theta^{j}$. The history of votes can be a valuable source of information as it may reveal something about the realizations of the previous voters' private signals. Let $\mu_{i}^{j} \equiv P\left(\theta^{j}=1 \mid h_{i}^{j}\right)$ indicate member $i^{j}$ 's beliefs about the state after observing the preceding votes (not yet taking his own signal into account) and updating using Bayes' rule. Thus, the optimal voting behavior for learning types can be characterized by the cutoff signal, $\bar{s}_{i, t=H}^{j}$ :

\footnotetext{
${ }^{11}$ Recall that the signals satisfy the monotone likelihood ratio property, see Duggan and Martinelli (2001) for how this translates into a voting rule characterized by a threshold crossing condition.
} 


$$
P\left(\theta^{j}=1 \mid \bar{s}_{i, t=L}^{j}, h_{i}^{j}\right)=1 / 2 \Longleftrightarrow \bar{s}_{i, t=L}^{j}=\frac{-2 \mu_{i}^{j}+\tau+1}{2 \tau}
$$

Member $i_{t=L}^{j}$ votes yes if $s_{i}^{j}>\bar{s}_{i, t=L}^{j}$ and no if $s_{i}^{j}<\bar{s}_{i, t=L}^{j}$. Again, (2) only holds for $\mu_{i}^{j} \in\left(\frac{1-\tau}{2}, \frac{1+\tau}{2}\right)$. If $\mu_{i}^{j} \leq \frac{1-\tau}{2}$ then member $i_{t=L}^{j}$ votes no for any signal realization and if $\mu_{i}^{j} \geq \frac{1+\tau}{2}$ he/she always votes yes. When voting is simultaneous there is no difference between the behavior of the informative type and the learning type.

Figure 2 illustrates how the cut-off signal varies with $\mu$ and $\tau$. For a larger $\mu$ the cut-off signal is lower, hence there is a greater probability that the expert's private signal will exceed the cut-off signal and the expert will vote yes. For $\tau<1$, the cut-off signal is irrelevant when $\mu \leq \frac{1-\tau}{2}$ or $\mu \geq \frac{1+\tau}{2}$.

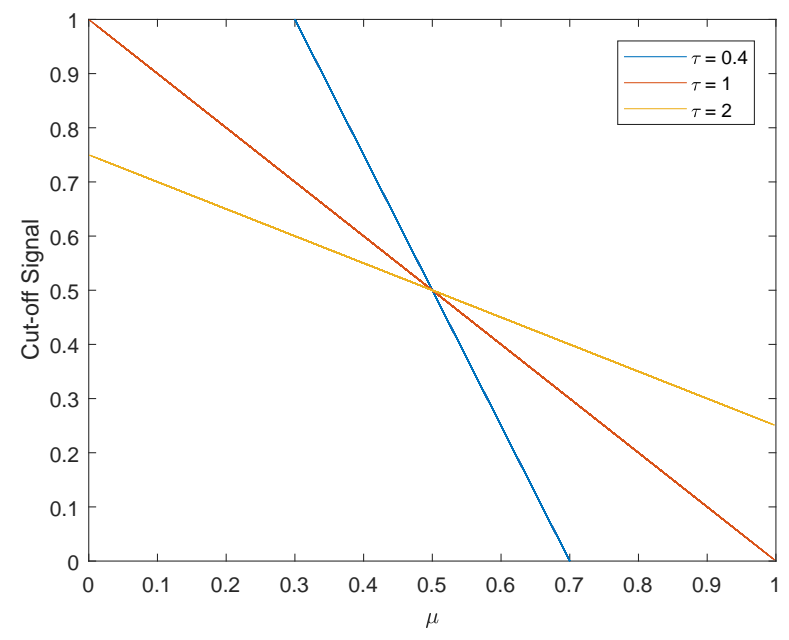

Figure 2: Cut-off Signal given $\mu$

\subsection{Herd voting}

We refer to the notion of local herd voting whenever a learning type is swayed by the history of votes. That is, when the learning type, following the cutoff rule, votes yes (no), whereas had he/she ignored the vote-history and followed the cutoff rule in (1), like the informative type, he/she would have voted no (yes). In addition, we term it local cascade voting if it is optimal for committee member $i_{t=L}^{j}$ to vote, say yes, for any possible private signal realization and, at the same time, had member $i_{t=L}^{j}$ ignored the vote-history he/she would have voted no after observing $s_{i, t=L}^{j}$. The formal definitions are: 
DEFINITION 1 (herd-voting): (i) Committee member $i_{t=L}^{j}$ engages in herd-yesvoting if

$$
\mu_{i}^{j} \in\left(\frac{1-\tau}{2}, \frac{1+\tau}{2}\right) \text { and } \frac{-2 \mu_{0}^{j}+\tau+1}{2 \tau}>s_{i, t=L}^{j}>\frac{-2 \mu_{i}^{j}+\tau+1}{2 \tau}
$$

(ii) Committee member $i_{t=L}^{j}$ engages in herd-no-voting if

$$
\mu_{i}^{j} \in\left(\frac{1-\tau}{2}, \frac{1+\tau}{2}\right) \text { and } \frac{-2 \mu_{0}^{j}+\tau+1}{2 \tau}<s_{i, t=L}^{j}<\frac{-2 \mu_{i}^{j}+\tau+1}{2 \tau}
$$

DEFINITION 2 (cascade-voting): (i) Committee member $i_{t=L}^{j}$ engages in cascadeyes-voting if

$$
\mu_{i}^{j} \geq \frac{1+\tau}{2} \text { and } s_{i, t=L}^{j}<\frac{-2 \mu_{0}^{j}+\tau+1}{2 \tau}
$$

(ii) Committee member $i_{t=L}^{j}$ engages in cascade-no-voting if

$$
\mu_{i}^{j} \leq \frac{1-\tau}{2} \text { and } s_{i, t=L}^{j}>\frac{-2 \mu_{0}^{j}+\tau+1}{2 \tau}
$$

Unless $\mu_{0}^{j} \notin\left(\frac{1-\tau}{2}, \frac{1+\tau}{2}\right)$ or $\mu_{0}^{j}=\mu_{i}^{j}$ (which is the case for the first voter) there will always be some private signal realizations whereby member $i_{t=L}^{j}$ engages in herd- or cascade voting under sequential polling. Note that cascade voting is not possible when $\tau \geq 1$, as there will always be some possible private signal realizations that shifts the beliefs about which state is more likely and thus the learning type pays attention to his/her signal. To this point, even when $\tau>1$ and $N$ is large the updated prior cannot hit 1 or 0 . For $\tau>1$ the cutoff point for any type is within the interval $\left(\frac{\tau-1}{2 \tau}, \frac{\tau+1}{2 \tau}\right)$ and we know that signal realizations sufficiently close to the cutoff point, which is within the interval $\left(\frac{\tau-1}{2 \tau}, \frac{\tau+1}{2 \tau}\right)$, are possible under both states of the world. Thus, one cannot conclude from the voting history alone that the state is certainly 1 or 0 .

When $\mu_{0}^{j} \notin\left(\frac{1-\tau}{2}, \frac{1+\tau}{2}\right)$ there is no private signal realization which can overcome the prior and informative- and learning types vote the same. In this case, learning is stuck from the beginning. Given $\mu_{0}^{j} \in\left(\frac{1-\tau}{2}, \frac{1+\tau}{2}\right)$ and $\mu_{0}^{j}<\mu_{i}^{j}$ the probability that member $i_{t=L}^{j}$ engages in herd-yes-voting can be computed as the probability that $s_{i, t=L}^{j}$ lands in the interval $\left[\frac{-2 \mu_{i}^{j}+\tau+1}{2 \tau}, \frac{-2 \mu_{0}^{j}+\tau+1}{2 \tau}\right]$. Similarly when $\mu_{0}^{j} \in\left(\frac{1-\tau}{2}, \frac{1+\tau}{2}\right)$ and $\mu_{0}^{j}>\mu_{i}^{j}$ and herd-no-voting is possible. Thus, a larger discrepancy between $\mu_{0}^{j}$ and $\mu_{i}^{j}$ implies that the probability of a herd vote increases. However, for $\tau<1$ and a sufficiently extreme 
$\mu_{i}^{j}$ the learning type will ignore his/her signal and cascade vote. This does not imply that all subsequent learning-types will cascade, as votes from informative types may reverse the beliefs about $\theta^{j}$. Even for $\tau<1$ a positive proportion of informative types ensures that learning never ceases and is unbounded given that $\mu_{0}^{j} \in\left(\frac{1-\tau}{2}, \frac{1+\tau}{2}\right)$.

\subsection{The likelihood function}

To estimate our voting model we have to specify its likelihood function. Recall that the state is independently drawn across the voting questions $j=1, \ldots, J$ and the private signals $\left\{s_{1}^{j}, \ldots, s_{N^{j}}^{j}\right\}$ are independent and identically distributed conditional on $\theta^{j}$. Therefore, the events $v^{j}$ and $v^{k \neq j}$ are independent and the likelihood of a sequence of votes over the set of voting questions can be written as

$$
P\left(\left\{v^{j}\right\}_{j=1}^{J} \mid \Phi\right)=\prod_{j=1}^{J} P\left(v^{j} \mid \Phi\right)
$$

Where $\Phi$ is the vector of parameters $\left\{\mu_{0}, \tau, \lambda, \xi\right\}$. To demonstrate how to derive $P\left(v^{j} \mid \Phi\right)$ we consider sequential voting and any voting sequence $v^{j}=v_{1}^{j}, \ldots, v_{N^{j}}^{j}$.

$$
\begin{array}{r}
P\left(\left\{v^{j}\right\} \mid \Phi\right)=\mu_{0}^{j} \prod_{i=1}^{N^{J}} P\left(v_{i}=1 \mid \Phi, h_{i}^{j}, \theta=1\right)^{v_{i}} P\left(v_{i}=0 \mid \Phi, h_{i}^{j}, \theta=1\right)^{1-v_{i}} \\
\quad+\left(1-\mu_{0}^{j}\right) \prod_{i=1}^{N^{J}} P\left(v_{i}=1 \mid \Phi, h_{i}^{j}, \theta=0\right)^{v_{i}} P\left(v_{i}=0 \mid \Phi, h_{i}^{j}, \theta=0\right)^{1-v_{i}}
\end{array}
$$

Conditional on the state and the voting history $h_{i}^{j}$, the individual votes are independent across the members. Thus, the vector of votes follows a multivariate mixture distribution, with mixing probability $\mu_{0}^{j}$. The state specific voting probabilities are calculated as follows: ${ }^{12}$

$$
\begin{aligned}
& P_{1, i} \equiv P\left(v_{i}^{j}=1 \mid \Phi, h_{i}^{j}, \theta=1\right)=\lambda P\left(s_{i}^{j}>\bar{s}_{i, t=L}^{j} \mid \Phi, h_{i}^{j}, \theta=1\right)+(1-\lambda) P\left(s_{i}^{j}>\bar{s}_{i, t=I}^{j} \mid \Phi, \theta=1\right) \\
& P_{0, i} \equiv P\left(v_{i}^{j}=1 \mid \Phi, h_{i}^{j}, \theta=0\right)=\lambda P\left(s_{i}^{j}>\bar{s}_{i, t=L}^{j} \mid \Phi, h_{i}^{j}, \theta=0\right)+(1-\lambda) P\left(s_{i}^{j}>\bar{s}_{i, t=I}^{j} \mid \Phi, \theta=0\right)
\end{aligned}
$$

\footnotetext{
${ }^{12}$ By the monotone likelihood ratio property of the signals it is ensured that $P_{1, i} \geq P_{0, i}$ and we can identify the state-specific voting probabilities. Identification in this setting is proven in a number of papers dealing with identification of mixture models such as Allman et al. (2009). Iaryczower and Shum (2012) use this argument to prove the identification of their structural model.
} 
To solve for $\bar{s}_{i, t=L}^{j}$ we need member $i$ 's updated probability that the state is good, given the history of votes. We do this recursively, inspired by the recursive procedure in Cipriani and Guarino (2014), whereby using Bayes rule

$$
\mu_{i}^{j} \equiv P\left(\theta^{j}=1 \mid h_{i}^{j}\right)=\frac{\mu_{i-1}^{j} P_{1, i-1}^{v_{i-1}}\left(1-P_{1, i-1}\right)^{1-v_{i-1}}}{\mu_{i-1}^{j} P_{1, i-1}^{v_{i-1}}\left(1-P_{1, i-1}\right)^{1-v_{i-1}}+\left(1-\mu_{i-1}^{j}\right) P_{0, i-1}^{v_{i-1}}\left(1-P_{0, i-1}\right)^{1-v_{i-1}}}
$$

for $i \geq 2$ and our base is $\mu_{1}^{j}=\mu_{0}^{j}$. If voting is simultaneous we can compute $P\left(v^{j}\right)$ in the same manner, with the important difference that all the committee members vote with an empty vote-history. In this way, informative and learning types follow the same cutoff-strategy. In Appendix D we consider and estimate the case where learning types are "naive" as in Eyster and Rabin (2010) and (incorrectly) believe that each previous person's action reflects solely that person's private information; as if everyone else is an informative type.

\section{Data}

In the United States the producers of new drugs are required to win approval from the FDA in order to market their products. The review process gives the FDA the option to refer a matter of drug approval to one of its advisory committees. Around half of the drugs that the FDA reviews goes to a committee - typically those where the available data renders decision making particularly difficult or the drug or disease involved is controversial (Moffitt, 2010). Advisory committees are intended to provide the FDA with independent opinions and recommendations from outside experts. Although the expert committees provide recommendations to the FDA, the FDA makes the final decisions. ${ }^{13}$ The committee meetings usually last an entire day. At the beginning of a meeting the FDA and the sponsor company present the data from clinical trials and their results regarding the risks and benefits of the drug or product under consideration. After the presentations the committee members deliberate and usually, after lengthy discussions, vote on one or more questions set out by the FDA beforehand. These questions are generally scientific in nature and can involve a range of subjects, including the assessment of a drug or biological product's efficacy, safety, or overall approvability.

There are currently 18 different advisory committees under the Center for Drug Eval-

\footnotetext{
${ }^{13}$ Guidance for Industry, Advisory Committees: Implementing Section 120 of the Food and Drug Administration Modernization Act of 1997.
} 
uation and Research, which handles medical drugs and some biological products. ${ }^{14}$ The committees are specialized on a particular disease or topic e.g. the Cardiovascular and Renal Drugs Advisory Committee or the Oncologic Drugs Advisory Committee. Each committee typically meets 1 to 4 times per year at the request of the FDA. On average a committee comprises of around a dozen members. Each committee has a chair, who leads the meetings, several regular scientific members (serving 4-year terms), plus a qualified consumer and sometimes a patient representative. ${ }^{15}$ Additional experts are usually added as temporary voting members to serve for a specific advisory committee meeting. Like regular members, the invited temporary members have recognized expertise in the relevant field. ${ }^{16}$ Temporary members can be invited outside experts, members of the center's consultancy pool, or members of other advisory committees.

Following the Draft Guidance for FDA Advisory Committees of 2007 the voting procedure changed from sequential to simultaneous voting. ${ }^{17} 18$ Under sequential voting the polling starts at one end of the committee table, at the chair's discretion, and continues in a stepwise fashion according to the seating plan of the meeting. The seating plan is jointly decided by the committee's executive secretary and the chair. In Appendix A we provide evidence that, based on observable member characteristics, there are no clear patterns in the way that the committee members are seated. When a meeting has several voting questions, which is often the case, the chair usually alternates so that voting starts at each end of the committee table at every other voting question (on few occasions also starting from the middle and going clockwise or counter-clockwise around the table). The chair also votes and is seated in a central position. Often, the members are allowed to accompany their votes with comments, motivation, or provisos.

\footnotetext{
${ }^{14}$ Approval of medical devices are reviewed by advisory committees under the Center for Devices and Radiological Health. We only consider committees under the Center for Drug Evaluation and Research, where meeting and voting procedures follow the same template.

${ }^{15}$ As stated by the FDA, the role of the consumer representative is to represent the consumer perspective and serve as a liaison between the committee and interested consumers and consumer organizations. The consumer representatives are usually experts in the field like the regular committee members. Patient representatives have experience with the disease either as a patient, or primary caregiver.

${ }^{16}$ Guidance for Industry, Advisory Committees: Implementing Section 120 of the Food and Drug Administration Modernization Act of 1997.

${ }^{17}$ In the transition from sequential to electronic voting some committee meetings used voting by a show of hands. We exclude these meetings from our analysis.

${ }^{18}$ Around the same time the voting procedure changed, the FDA Amendments Act of 2007 was passed by Congress. The law extended the authority to levy fees on companies applying for drug approvals, expanded clinical trial guidelines for pediatric drugs, enhanced the authorities to require post-approval studies, and established a limit on the number of committee members with financial conflicts.
} 
Under simultaneous voting the members place their votes with electronic voting pads and after the votes have been locked in they sequentially go on the record and state what they voted and give comments. The order of announcements follows the seating plan of the meeting and the chair decides at which end of the table to begin. As with sequential voting, the chair usually alternates so that the announcements starts at each end of the committee table at every other voting question.

The voting members also have the option to abstain, although they rarely do so. In our data, 1.2 percent of the sequential votes are abstentions and 2.7 percent of the simultaneous votes are abstentions. For simplicity we ignore abstentions in our analysis (the individual abstentions drop out as if they had not been placed).

Our data source is the full set of meeting transcripts that can be downloaded via www.fda.gov. The public records start in 1996 and we have data until June 2014. We consider committee meetings with one or more binary voting questions on the agenda and where the overall topic concerns approval of a new (or supplementary) drug or biological product. For sequential voting, this gives us 138 committee meetings and 375 binary voting questions with the full sequence of votes and for simultaneous voting it is 189 committee meetings and 438 voting questions. In total the data consists of 10,466 yes or no votes. A "yes" vote is always associated with a favorable assessment of the relevant drug or biological product. This means that on a few occasions we reverse the votes, for example on the voting question: "Does this application raise concerns about safety findings in Vimizim in MPS IVA patients?" On average a committee comprises of 13 members, with a minimum of 5 members and a maximum of 28 members.

For each committee meeting, we indicate whether voting is simultaneous or sequential, the name of the advisory committee, type of application and proposed trade name, and a score on the FDA reviewer(s) assessment of efficacy, safety, and approval. ${ }^{19}$ Our data covers 15 different topical committees. The type of application is either a New Drug Application (NDA), a Biologic License Application (BLA), a supplemental New Drug Application (sNDA), or a supplemental Biologic License Application (sBLA). ${ }^{20}$

\footnotetext{
${ }^{19}$ In some cases, multiple drugs or products are considered on the same day and meetings are then split between morning and afternoon sessions.

${ }^{20}$ Companies are allowed to make changes to drugs and biological products or their labels after they have been approved. To change a label, market a new dosage or strength, or change the way the treatment is manufacturing, a company must submit a supplemental new drug application (sNDA) or supplemental Biologic License Application (sBLA).
} 
We also record the wording of the voting question and classify it depending on whether the question is about efficacy, safety, approval, or other (e.g. questions about methodology, dose, or labeling). Efficacy questions concern whether a specific clinical trial demonstrates that the treatment is effective. For example, "Based on the prespecified analysis, is there sufficient evidence to conclude that gabapentin is effective in treating moderate to severe vasomotor symptoms, VMS, due to menopause?". An example of a safety question is, "Do the data provide sufficient evidence of safety of Advair Diskus for the treatment of chronic obstructive bronchitis?" An example of a risk vs. benefit question is, "Taking into consideration the overall risks and benefits of orlistat, do you recommend that the drug be approved for marketing for the management of obesity?"

The FDA reviewer score is based on the FDA presentations and introductory remarks. Before each committee meeting the FDA's review team analyses the efficacy and safety studies in question and prepares presentations to be held in front of the committee. These presentations take place before the voting stage and the reviewers are not members of the committee and do not vote. The FDA reviewer score on efficacy $(1,0,-1)$ reflects the review team's conclusions regarding efficacy of the proposed drug or biological product. This revolves around the primary endpoints of the efficacy studies. These studies are often placebo controlled trials, but can also be non-inferiority or superiority studies with respect to an already approved comparator. If the FDA reviewer(s) state that all the primary endpoints were met (usually with respect to pvalues less than 0.05 ) in all the efficacy studies we code the efficacy score as 1 . If the efficacy results are mixed or the FDA reviewer has major methodology concerns we code the efficacy score as 0 . If the FDA reviewer concludes that the drug or product has no effect we code the efficacy score as -1 .

Similarly for safety. The FDA reviewer score on safety $(1,0,-1)$ reflects the review team's conclusions regarding safety issues and adverse events. If the reviewer concludes that the safety profile is not worse than already approved drugs or products for the same indication we record a score of +1 . The same if the reviewer states that the safety studies reveal no significant safety concerns. On the other hand, if the FDA reviewer expresses serious safety concerns, also with respect to what is the standard for the relevant indication, we code the safety score as -1. As an example: "In summary, the safety findings reveal the incidence of toxicity across multiple organ systems, which seems excessive for an adjuvant therapy without a survival advantage." If neither ex- 
plicit positive or negative conclusions are drawn from the safety review we code the safety score as 0. Finally, the approval score simply adds the efficacy score to the safety score. ${ }^{21}$ Where the total score is 1 or higher, the FDA reviewer score for approval questions will be 1 , similarly when it is -1 or lower, the FDA reviewer score will be -1 . Questions that are classified as 'other' do not receive an FDA reviewer score. Table 1 indicates the frequency of voting questions in each group.

At the voting question level, we record the individual votes. For meetings with simultaneous voting, we order the votes in the way that the committee members announce them as they go on the record after the votes have been locked in. For sequential voting, the votes are obviously entered according the order in which they are cast. Under sequential voting, we have 20 voting questions with low data quality in the sense that the voting order was interrupted during voting (11), the voting question was modified after the first vote was given (5), or members did not precisely specify their vote (4). In the latter case, we include a yes or no vote depending on whether the member expressed himself/herself positively or negatively on the voting question. These voting questions are all included in our empirical analysis. ${ }^{22}$

At the vote level, we register the name and educational background of the voter. We also indicate the gender, whether the voter is a consumer or patient representative, and whether the voter is a regular or temporary committee member. All this information, except for gender, appears in the meeting transcripts or the summary minutes. Table 2 indicates the frequency of voter characteristics.

\footnotetext{
${ }^{21}$ There are some missing data for the FDA reviwer score. Specifically, meetings at the Cardiovascular and Renal Drugs Advisory Committee do not use FDA presentations until the end of 2005. For these meetings we insert reviewer scores of 0 .

${ }^{22}$ None of our results or estimates significantly change depending on whether we include these these observations or not.
} 


\begin{tabular}{|c|c|c|c|}
\hline & Sequential & Simultaneous & All \\
\hline \multicolumn{4}{|l|}{ FDA Reviewer Score } \\
\hline-1 & 37 & 26 & 63 \\
\hline 0 & 134 & 172 & 306 \\
\hline 1 & 51 & 119 & 170 \\
\hline No score & 153 & 120 & 273 \\
\hline \multicolumn{4}{|l|}{ Question type } \\
\hline Efficacy & 75 & 83 & 158 \\
\hline Other & 153 & 120 & 273 \\
\hline Risk v. Benefit & 126 & 179 & 305 \\
\hline Safety & 21 & 56 & 77 \\
\hline \multicolumn{4}{|l|}{ Application type } \\
\hline Non-supplementary & 298 & 325 & 623 \\
\hline Supplementary & 77 & 113 & 190 \\
\hline \multicolumn{4}{|l|}{ Product category } \\
\hline Drug & 349 & 336 & 685 \\
\hline Biologic & 26 & 102 & 128 \\
\hline \multicolumn{4}{|l|}{ Committee } \\
\hline Anesthetic and Life Support & 1 & 13 & 14 \\
\hline Anti Infective & 25 & 37 & 62 \\
\hline Anti Viral & 16 & 16 & 32 \\
\hline Arthritis & 13 & 31 & 44 \\
\hline Cardiovascular and Renal & 76 & 31 & 107 \\
\hline Dermatologic and Ophthalmic & 11 & 17 & 28 \\
\hline Endocrinologic and Metabolic & 61 & 43 & 104 \\
\hline Gastrointestinal & 24 & 44 & 68 \\
\hline Medical Imaging & 2 & 3 & 5 \\
\hline Nonprescription & 5 & 7 & 12 \\
\hline Oncologic & 70 & 36 & 106 \\
\hline Peripheral and Central Nervous System & 20 & 42 & 62 \\
\hline Psychopharmacologic & 14 & 42 & 56 \\
\hline Pulmonary Allergy & 16 & 49 & 65 \\
\hline Reproductive Health & 21 & 27 & 48 \\
\hline Total & 375 & 438 & 813 \\
\hline
\end{tabular}

Table 1: Voting Question Characteristics 


\begin{tabular}{lcc}
\hline \hline & Frequency & Percent \\
\hline Degree & & \\
Medical & 6,160 & 58.86 \\
PhD & 3,160 & 30.19 \\
Other degree & 698 & 6.67 \\
No degree & 448 & 4.28 \\
& & \\
Gender & & \\
Male & 6,863 & 65.6 \\
Female & 3,603 & 34.4 \\
& & \\
Type & & \\
Regular committee member & 5,734 & 54.8 \\
Temporary committee member & 3,625 & 34.6 \\
Consumer or patient representative & 1,107 & 10.6 \\
& & \\
Total & 10,466 & 100 \\
\hline \hline
\end{tabular}

Table 2: Voter Characteristics

\section{Descriptive analysis}

In this section, we present descriptive statistics and use reduced-form (regression) techniques to assess whether there are indications of herd behavior in the data. Our initial analysis is confirmatory: The main insights are that the probability of a committee member voting the same as the person seated before him/her and the probability of a unanimous vote outcome are significantly lower under simultaneous voting. This further warrants a direct empirical test and estimation of our theoretical model.

To obtain precursory insights into voting outcomes under sequential and simultaneous voting, we construct the following variables at the voting-question level; 1) the probability that, for a specific vote question, a member's vote matches the preceding $\left.\operatorname{vote}^{23}, 2\right)$ an indicator variable that takes the value 1 if the outcome of the vote is unanimous, 3) the size of the majority (as a percentage), and 4) the percentage of yes

\footnotetext{
${ }^{23}$ For simultaneous and sequential voting, this is calculated as the number of votes that are identical to the previous vote divided by the total number of votes excluding the first vote. The order we use follows the seating order.
} 
votes.

Descriptive statistics for these variables are presented in Table 3. Under sequential voting, the average probability that a member's vote is the same as the preceding vote is $82 \%$ whereas under simultaneous voting it is $77 \%$. The difference is significant. Under sequential voting $48 \%$ of vote outcomes are unanimous whereas under simultaneous voting $29 \%$ of vote outcomes are unanimous. Figure 3 shows the distribution of the percentage of yes votes for a given voting question. Clearly, there appears to be more agreement in votes under the sequential procedure.

\begin{tabular}{lcccccccc}
\hline \hline & & & & & & \multicolumn{3}{c}{ Mean by Voting Rule } \\
\cline { 7 - 9 } Variable & Obs. & Mean & Std. Dev. & Min & Max & Sequential & Simultaneous & Difference \\
\hline $\operatorname{Pr}\left(v_{i}=v_{i-1}\right)$ & 813 & 0.79 & 0.212 & 0.1 & 1 & 0.817 & 0.766 & $-0.051^{* * *}$ \\
Unamimous & 813 & 0.375 & 0.484 & 0 & 1 & 0.477 & 0.288 & $-0.19^{* * *}$ \\
Majority size & 813 & 0.853 & 0.154 & 0.5 & 1 & 0.871 & 0.838 & $-0.033^{* * *}$ \\
Percent yes & 813 & 0.637 & 0.36 & 0 & 1 & 0.664 & 0.614 & $-0.05^{*}$ \\
\hline \hline
\end{tabular}

Notes: $* * * p<0.01, * * p<0.05, * p<0.1$.

Table 3: Descriptive Statistics for Vote Outcomes
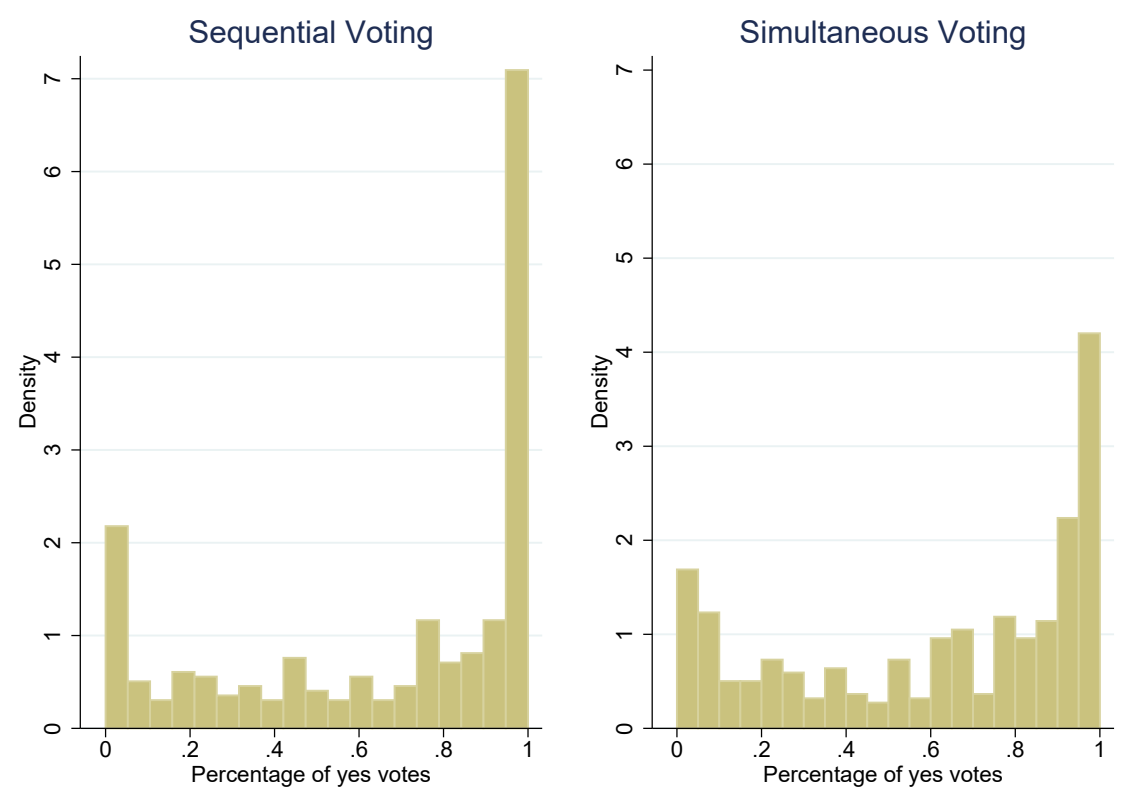

Figure 3: Agreement of Votes 
To obtain further insight into which vote characteristics are correlated with vote outcomes we regress the vote outcome variables on vote characteristics and an indicator variable that takes on the value 1 if voting is simultaneous. Table 4 presents the regression results using ordinary least squares. Controlling for observable vote characteristics, a change from sequential to simultaneous voting reduces the probability that a member's vote is the same as the previous vote by 6.6 percentage points. The probability of a unanimous outcome is reduced by 19 percentage points on average by the switch to simultaneous voting. The size of the majority and percentage of yes votes are also reduced by the change to simultaneous voting. Other than the FDA reviewer score, vote characteristics such as committee size, committee and vote question type do not consistently have a significant effect on the vote outcome variables. In sum, the initial analysis provides results consistent with what we would expect if there was momentum effects in sequential voting.

The reduced-form results suggest that there is "something going on" regarding the voting procedure. However, we cannot rule out the possibility that voting outcomes may be driven by more extreme priors for the voting questions under the sequential procedure, which would lead to more agreement (regardless of the voting procedure). This is something that our reduced form model cannot capture and even if we believe that, on average, the priors are similar for the sequential and simultaneous voting questions, a reduced-form model cannot speak to the mechanism that causes more agreement in the case of sequential voting. A structural approach is invaluable in this situation to explicitly incorporate the unobserved prior for each voting question and the experts' private information and provide estimates that have a clear interpretation in the context of a model of herd behavior. Whereas in the reduced-form model we have looked at outcomes at the voting question level, in our structural model, we use information from the complete vote sequence to learn something about herd behavior in advisory committees. Ultimately, using our structural model, we can also say something about which voting procedure leads to more efficient information aggregation or outcomes that reflect the true state. 


\begin{tabular}{|c|c|c|c|c|}
\hline & & Depe & ndent variable & \\
\hline & $\operatorname{Pr}\left(v_{i}=v_{i-1}\right)$ & Unamimous & Majority size & Percent yes \\
\hline Simultaneous & $\begin{array}{c}-0.0660^{* * *} \\
(0.0178)\end{array}$ & $\begin{array}{c}-0.194^{* * *} \\
(0.0400)\end{array}$ & $\begin{array}{c}-0.0443^{* * *} \\
(0.0131)\end{array}$ & $\begin{array}{c}-0.0888^{* * *} \\
(0.0341)\end{array}$ \\
\hline Committee Size & $\begin{array}{l}0.000343 \\
(0.00234)\end{array}$ & $\begin{array}{c}-0.0168^{* * *} \\
(0.00496)\end{array}$ & $\begin{array}{l}-0.00151 \\
(0.00173)\end{array}$ & $\begin{array}{l}-0.000888 \\
(0.00379)\end{array}$ \\
\hline FDA Reviewer Score $=-1$ & $\begin{array}{c}-0.0974^{* * *} \\
(0.0296)\end{array}$ & $\begin{array}{c}-0.142^{* *} \\
(0.0618)\end{array}$ & $\begin{array}{c}-0.0564^{* * *} \\
(0.0205)\end{array}$ & $\begin{array}{c}-0.139 * * * \\
(0.0477)\end{array}$ \\
\hline FDA Reviewer Score $=1$ & $\begin{array}{c}0.0737^{* * *} \\
(0.0205)\end{array}$ & $\begin{array}{c}0.171^{* * *} \\
(0.0475)\end{array}$ & $\begin{array}{c}0.0611^{* * *} \\
(0.0146)\end{array}$ & $\begin{array}{c}0.185^{* * *} \\
(0.0349)\end{array}$ \\
\hline Supplementary & $\begin{array}{l}0.00928 \\
(0.0236)\end{array}$ & $\begin{array}{c}0.0162 \\
(0.0489)\end{array}$ & $\begin{array}{l}0.00792 \\
(0.0170)\end{array}$ & $\begin{array}{l}-0.0238 \\
(0.0370)\end{array}$ \\
\hline Biologic & $\begin{array}{c}0.0250 \\
(0.0252)\end{array}$ & $\begin{array}{c}0.0630 \\
(0.0479)\end{array}$ & $\begin{array}{c}0.0214 \\
(0.0183)\end{array}$ & $\begin{array}{c}0.0148 \\
(0.0502)\end{array}$ \\
\hline Efficacy & $\begin{array}{c}0.0222 \\
(0.0238)\end{array}$ & $\begin{array}{l}0.00597 \\
(0.0510)\end{array}$ & $\begin{array}{c}0.0125 \\
(0.0172)\end{array}$ & $\begin{array}{c}0.0363 \\
(0.0396)\end{array}$ \\
\hline Risk vs. Benefit & $\begin{array}{c}0.0149 \\
(0.0209)\end{array}$ & $\begin{array}{l}0.00130 \\
(0.0464)\end{array}$ & $\begin{array}{c}0.0144 \\
(0.0147)\end{array}$ & $\begin{array}{l}-0.0218 \\
(0.0358)\end{array}$ \\
\hline Safety & $\begin{array}{c}0.0271 \\
(0.0264)\end{array}$ & $\begin{array}{c}0.0525 \\
(0.0629)\end{array}$ & $\begin{array}{l}0.00629 \\
(0.0201)\end{array}$ & $\begin{array}{c}0.0864^{* *} \\
(0.0425)\end{array}$ \\
\hline $\begin{array}{l}\text { Committee Fixed Effects } \\
\text { Constant }\end{array}$ & $\begin{array}{c}\text { yes } \\
0.682^{* * *} \\
(0.114)\end{array}$ & $\begin{array}{c}\text { yes } \\
0.661^{* * *} \\
(0.217)\end{array}$ & $\begin{array}{c}\text { yes } \\
0.805^{* * *} \\
(0.0704)\end{array}$ & $\begin{array}{c}\text { yes } \\
0.394^{* * *} \\
(0.108)\end{array}$ \\
\hline $\begin{array}{l}\text { Observations } \\
\text { R-squared }\end{array}$ & $\begin{array}{c}813 \\
0.115\end{array}$ & $\begin{array}{c}813 \\
0.134\end{array}$ & $\begin{array}{c}813 \\
0.103\end{array}$ & $\begin{array}{c}813 \\
0.123\end{array}$ \\
\hline
\end{tabular}

Notes: Standard errors are clustered by meeting. Base category is Non-supplementary, Anesthetic and Life Support Drugs with a reviewer score of 0 or no reviewer score. $* * * p<0.01, * * p<0.05, * p<0.1$.

Table 4: Reduced-form Results

\section{Estimation and identification}

In this section, we describe the specification of the prior and the estimation of our model. To conclude, we provide some intuition on which variation in the data allows us to identify the parameters of the model.

To make the model tractable, we place a parametric restriction on the prior. This is in line with previous literature by Iaryczower and Shum (2012) and Camara and Dupius (2014). We allow the prior $\mu_{0}^{j}$, the common belief that the correct answer to 
the voting question is yes, to depend parametrically on characteristics of the voting question captured by $X_{j}$ (e.g. FDA reviewer score and committee) via the following logit formulation:

$$
\mu_{0}^{j}\left(X_{j} ; \beta\right)=\frac{\exp \left(X_{j}^{\prime} \beta\right)}{1+\exp \left(X_{j}^{\prime} \beta\right)} \in(0,1)
$$

This specification implies that there are certain observable vote characteristics that have an effect on the probability of the state being "yes" or "no". The state for each voting question $j$ is determined by these characteristics and a question-specific unobserved shock term drawn from a standard logistic distribution. In Appendix B we elaborate on how this specification can accommodate correlation in the true state for voting questions that are part of the same meeting.

The parameters to be estimated are $\beta, \tau$ and $\lambda$. To recover the parameter estimates, we maximize the likelihood function (3) directly, using the full dataset of 10,466 individual votes. We take the log of the likelihood function and minimize the negative log-likelihood function using the quasi-Newton algorithm for unconstrained optimization (fminunc in Matlab). Optimization using the Nelder-Mead simplex direct search algorithm produces the same results (fminsearch in Matlab). Results are robust to different starting values. Standard errors are calculated by taking the square root of the diagonal elements of the inverse estimated Hessian of the likelihood function at the solution. ${ }^{24}$

Regarding the model's identification, both the degree of agreement among the votes i.e. how many yes vs. no votes, and the specific sequence of votes are important. The common prior induces a correlation of votes; all experts tend to receive higher private signals when the state of the world is "yes." Hence, $\beta$ is identified by the number of yes vs. no votes at the vote question level. A higher precision of information, $\tau$, will also contribute towards more agreement in votes, but this effect will be identified by agreement in votes that exists across voting questions and concerns agreement in both directions (favorable and unfavorable). Hence, to identify $\tau$ we rely on multiple voting questions with different priors.

The proportion of learning types $\lambda$ is identified by the sequence of votes. Given

\footnotetext{
${ }^{24}$ We tested the model using simulated datasets and verified that our procedure yields reasonably precise, unbiased estimates of the parameters of the model.
} 
the prior and $\tau$, we can identify how likely it is that a voter is a learning type or a informative type based on how they vote in response to previous voters. Intuitively, if we see a long sequence of "yes" votes, and thereafter a voter who votes "no", this voter is more likely to be an informative type. ${ }^{25}$ Another important aspect for identification is that we have both simultaneous and sequential data. The fact that we have access to simultaneous data where we know $\lambda$ is zero (no learning) helps us to better estimate the prior and $\tau$, hence we can more effectively disentangle the effects of $\mu_{0}, \tau$, and $\lambda$.

\section{$6 \quad$ Estimation results}

In this section, we describe our results for the voting model introduced in Section 2. We first present the estimates of the model parameters and then discuss the frequency of herd voting.

\subsection{Estimates}

Table 5 presents the estimates and the standard deviations for the parameters of the model. We use information on the FDA reviewer score and application type (supplementary or non-supplementary) to characterize the prior. We find that our estimates of $\lambda$ and $\tau$ are robust to the inclusion of more vote characteristics in the specification of the prior, e.g. inclusion of committee fixed effects and type of voting question. We select this specification as it is parsimonious, while at same time providing a good sense of the range of $\mu_{0}$. In Appendix $\mathrm{C}$, we provide the parameter estimates for a model where we estimate a prior for each meeting (327 in total).

We find that on average $46 \%$ of committee members are learning types. Thus $46 \%$ of committee members take into consideration the vote history when placing their vote. However, this does not mean that $46 \%$ of committee members actually herd, that is, change their vote from what it would have been if ignoring the vote history. We discuss our approach to quantifying herd voting in the following subsection.

Additionally, we find that the precision of information for the FDA Advisory Committees is quite high $(\tau=1.28)$. This implies that the probability that a member gets an incorrect signal (i.e. a signal $<0.5$ when the state is 1 , or a signal $>0.5$ when the state is 0 ) is $20 \%$. Since we estimate a $\tau$ greater than 1 , we find that cascade-voting, which

\footnotetext{
${ }^{25}$ Indeed, we see that if we scramble our actual data and re-estimate the model we get a different estimate for lambda.
} 
is a theoretical possibility in our model, never occurs in the FDA Advisory Committees.

Estimates of the average common prior $\mu_{0}$ for categories of voting questions can be computed using $\beta$. For example, the average prior for voting questions relating to non-supplementary applications with an FDA reviewer score of -1 can be computed as $\frac{\exp (-0.19)}{1+\exp (-0.19)}=0.45$. Estimated average priors range from 0.37 to 0.74 . As we would expect there is a positive relationship between FDA reviewer score and the estimated average common prior.

\begin{tabular}{lcc}
\hline \hline Parameter & Estimate & $\mathrm{SD}$ \\
\hline$\tau$ & 1,28 & 0,03 \\
$\lambda$ & 0,46 & 0,04 \\
$\beta_{\text {nonsupp },-1}$ & $-0,19$ & 0,10 \\
$\beta_{\text {nonsupp }, 0}$ & 0,23 & 0,05 \\
$\beta_{\text {nonsupp }, 1}$ & 1,05 & 0,08 \\
$\beta_{\text {nonsupp }, \text { other }}$ & 0,26 & 0,06 \\
$\beta_{\text {supp },-1}$ & $-0,50$ & 0,20 \\
$\beta_{\text {supp }, 0}$ & 0,17 & 0,10 \\
$\beta_{\text {supp }, 1}$ & 0,29 & 0,13 \\
$\beta_{\text {supp }, \text { other }}$ & 0,32 & 0,09 \\
\hline \hline
\end{tabular}

Table 5: Estimation Results

\subsection{Herd behavior}

In this subsection, we investigate the prevalence of actual herd votes. Using our structural model and the estimated parameters we are able to construct a simulated dataset of votes under sequential and simultaneous voting, and by comparing the simulated individual votes under sequential and simultaneous voting we can directly identify how many committee members herded.

We simulate a dataset of 2000 vote questions which are voted on by 13 committee members (the average size of an FDA Advisory Committee in the data) under both a sequential and simultaneous procedure. In total the simulated dataset comprises of 52,000 individual votes. Votes are simulated using the structural voting model and the estimated parameters values of $\tau=1.28$ and $\lambda=0.46$. Our $\beta$ for all 2000 voting 
questions is 0.6 which implies an average prior of 0.65 . Specifically, our simulation procedure is as follows; 1 ) given $\mu_{0}$ each voting question is assigned a state, 2) contingent on the true state, and given $\tau$, we draw private signals for each voter, for each voting question, 3) with probability $\lambda$ a voter is assigned to be a learning type, 4) given the assigned signals, we simulate how voting would take place if voting was simultaneous and finally 5) given the assigned signals, types and $\lambda$ we simulate how voting would take place if voting was sequential. Thus, what we have is essentially the same voters voting on the same voting question, once under simultaneous rule, and once under the sequential rule. We then compare the simulated individual votes under sequential and simultaneous rule for each voting question and find that $17 \%$ of learning types actually herd. ${ }^{26}$ This implies that, on average, almost $8 \%$ of all the votes are herd votes.

Although a completely different setting, we can compare our estimates to Cipriani and Guarino (2014) who estimate a structural model with financial transactions data. In their model, herding is possible due to uncertainty about whether an informational event has occurred. If an informational event has occurred, some traders obtain private information on whether the event is positive or negative in terms of the new asset value. If no event has occurred, all traders are noise traders. The market maker updates the price more slowly than an informed trader would (i.e. being informed the informed trader knows if a shock has occurred). As a result, an informed trader may herd and follow the previous traders even if his/her signal is contradictory. Cipriani and Guarino (2014) estimate the informed traders' signals to be relatively imprecise; incorrect $40 \%$ of the time. During event days the proportion of informed traders is $42 \%$ (the remaining are noise traders). On information-event days, $2 \%$ (4\%) of informed traders herd-buy (sell) causing informational inefficiencies in the market.

\section{Heterogeneity in herd behavior}

In this section, we exploit the fact that our data contains information on individual voters and extend the model to allow for heterogeneity in herd behavior. As before, we first undertake a reduced form analysis to obtain initial insight into how member characteristics are correlated with measures of voting behavior. Thereafter, we adjust the structural model in order to incorporate voter characteristics and re-estimate the

\footnotetext{
${ }^{26}$ We also construct simulated datasets with different $\beta$ and find that this proportion of herding types is fairly stable. The proportion of learners that are herders is however sensitive to $\tau$; specifically a lower $\tau$ increases the proportion of herders.
} 
model.

\subsection{Descriptive analysis}

To obtain indications of herd voting at the individual level, we construct an indicator variable that takes the value 1 when voter $i$ votes against the prevailing majority, as calculated up until voter $i$. We drop voters 1, 2, 3 and 4 from the sample on grounds that early voters have less information on which to base their vote. ${ }^{27}$ We regress this variable, which we call Vote against Majority, on a set of voter characteristics including educational background, gender, whether or not the committee member is a regular member, whether or not the committee member is a consumer or patient representative and seat number, as well as on interactions of the these variables with an indicator variable Sequential that takes on the value 1 when voting is conducted sequentially. We should note here that voting with the prevailing majority under sequential voting is only indicative of herding, as of vote clustering, and clearly voting against the majority does not preclude herd voting (something that our structural model takes into account). For example, if the vote sequence is yes, yes, yes, no, no then the sixth member may herd no-vote, as the fourth and fifth votes indicate relatively strong "bad" signals.

Table 6 presents the results for a simple OLS specification. ${ }^{28}$ We first note that voters are significantly, increasingly less likely to vote against the majority as their seat number increases under sequential voting, this effect is not present under simultaneous voting. Secondly, we find that the coefficient on the interaction term between Regular Committee Member and Sequential is positive and significant. Hence, we find that regular committee members are significantly more likely to go against the prevailing majority as indicated by the vote history under sequential voting relative to simultaneous voting. This provides some initial evidence that it would be a worthwhile exercise to incorporate voter heterogeneity into the structural model, and in particular, to make a distinction between regular and other types of committee members.

\footnotetext{
${ }^{27}$ Results are qualitatively similar for other thresholds.

${ }^{28}$ Results are qualitatively similar if we use a Logit model, Probit model or a fixed effects model with vote question fixed effects.
} 


\begin{tabular}{|c|c|}
\hline Dep. var.: Vote against Majority & \\
\hline \multirow[t]{2}{*}{ Seat } & 0.00190 \\
\hline & $(0.00176)$ \\
\hline \multirow[t]{2}{*}{ Regular } & -0.0222 \\
\hline & $(0.0141)$ \\
\hline \multirow[t]{2}{*}{$\mathrm{PhD}$} & 0.0275 \\
\hline & $(0.0275)$ \\
\hline \multirow[t]{2}{*}{ Medical } & 0.0135 \\
\hline & $(0.0281)$ \\
\hline \multirow[t]{2}{*}{ Consumer Patient Rep. } & $0.0613^{* *}$ \\
\hline & $(0.0291)$ \\
\hline \multirow[t]{2}{*}{ Male } & 0.00523 \\
\hline & $(0.0146)$ \\
\hline \multirow[t]{2}{*}{ Seat $\times$ Sequential } & $-0.00637^{* *}$ \\
\hline & $(0.00301)$ \\
\hline \multirow[t]{2}{*}{ Regular $\times$ Sequential } & $0.0505^{* *}$ \\
\hline & $(0.0227)$ \\
\hline \multirow[t]{2}{*}{$\mathrm{PhD} \times$ Sequential } & -0.0349 \\
\hline & $(0.0396)$ \\
\hline \multirow[t]{2}{*}{ Medical $\times$ Sequential } & -0.0233 \\
\hline & $(0.0396)$ \\
\hline \multirow[t]{2}{*}{ Consumer Patient Rep. $\times$ Sequential } & -0.00973 \\
\hline & $(0.0427)$ \\
\hline \multirow[t]{2}{*}{ Male $\times$ Sequential } & 0.0155 \\
\hline & $(0.0219)$ \\
\hline \multirow[t]{2}{*}{ Constant } & -0.00805 \\
\hline & $(0.0530)$ \\
\hline Vote Characteristics & yes \\
\hline Observations & 7,040 \\
\hline R-squared & 0.025 \\
\hline
\end{tabular}

Notes: OLS estimation. Standard errors are clustered by meeting. $* * * p<0.01, * * p<0.05, * p<0.1$.

Table 6: Reduced-form Results - Heterogeneity

\subsection{Estimation results}

To incorporate differences in the probability of being a learning type across voters we specify $\lambda$ as a linear function of observable voter characteristics; $\lambda=\lambda_{0}+\Delta \lambda \cdot \mathbf{I}$, where I is a vector of indicator variables for the voter characteristics (e.g regular committee member, $\mathrm{PhD}$ ). With this adjustment to the model, we again maximize the likelihood 
function (3) directly. In the model, we assume learning types are aware of how $\lambda$ varies across voters. We can identify a different $\lambda$ for voters with certain characteristics by using variation in how voters with different characteristics repsond to the sequence of previous votes under sequential voting, as well as how subsequent voters react to this.

Table 7 presents the parameter estimates and standard errors. The results from the previous model (baseline) are included for comparison. In column 3, the estimated intercept for $\lambda$ represents the average probability that a temporary member is a learning type. On average the $\lambda$ for a temporary committee members is $59 \%$, for regular committee members it is $43 \%$ and for consumer/patient representatives it is $29 \%$. In Table 8 we provide an overview of the composition of these groups under sequential voting in terms of educational background and gender.

The low proportion of learning types among regular members compared to temporary members could be due to the fact that these members regularly participate in advisory meetings. This process would make their self-esteem and esteem as expert panelists fairly settled and potentially turn some regular "learning" members into expressive (informative) voters. With respect to social conformity, some experiments demonstrate that subjects are more likely to conform when grouped with strangers as opposed to friends (McKelvey and Kerr, 1988). We also find that consumer or patient representatives (which make up $10 \%$ of voters) are the least likely to herd. This result may in part be driven by the fact that these voters have an inherent bias. Cooper and Golec (2017) find consumer representatives are more likely to vote against drugs whereas patient representatives are more likely to vote for drugs.

In column 5 we include indicator variables for Male and $\mathrm{PhD}$. The results suggest that gender and whether or not an expert has a $\mathrm{PhD}$ has little impact on $\lambda$. The relationship between gender and conformity has been studied extensively in the social conformity literature. The results are mixed, however, Eagly and Carli (1981) performed a meta-analysis of 148 studies of influenceability and find that women are more persuadable and more conforming than men in group pressure situations that involve surveillance. 


\begin{tabular}{|c|c|c|c|c|c|c|}
\hline \multirow[b]{2}{*}{ Parameter } & \multicolumn{2}{|c|}{ Baseline } & \multicolumn{2}{|c|}{ Extension 1} & \multicolumn{2}{|c|}{ Extension 2} \\
\hline & Estimate & $\mathrm{SD}$ & Estimate & $\mathrm{SD}$ & Estimate & $\mathrm{SD}$ \\
\hline$\tau$ & 1,28 & 0,07 & 1,28 & 0,03 & 1,28 & 0,03 \\
\hline$\lambda_{0}$ & 0,46 & 0,03 & 0,59 & 0,06 & 0,58 & 0,07 \\
\hline$\Delta \lambda_{\text {Regular }}$ & & 0,06 & $-0,16$ & 0,07 & $-0,16$ & 0,07 \\
\hline$\Delta \lambda_{\text {ConsumerPatientRep }}$ & & & $-0,30$ & 0,11 & $-0,29$ & 0,11 \\
\hline$\Delta \lambda_{P h D}$ & & & & & 0,04 & 0,06 \\
\hline$\Delta \lambda_{\text {Male }}$ & & & & & 0,01 & 0,06 \\
\hline$\beta_{\text {nonsupp },-1}$ & $-0,19$ & 0,11 & $-0,20$ & 0,10 & $-0,20$ & 0,10 \\
\hline$\beta_{\text {nonsupp }, 0}$ & 0,23 & 0,10 & 0,22 & 0,05 & 0,22 & 0,05 \\
\hline$\beta_{\text {nonsupp }, 1}$ & 1,05 & 0,05 & 1,05 & 0,08 & 1,05 & 0,08 \\
\hline$\beta_{\text {nonsupp }, \text { other }}$ & 0,26 & 0,08 & 0,24 & 0,06 & 0,24 & 0,06 \\
\hline$\beta_{\text {supp },-1}$ & $-0,50$ & 0,06 & $-0,44$ & 0,20 & $-0,46$ & 0,20 \\
\hline$\beta_{\text {supp }, 0}$ & 0,17 & 0,20 & 0,16 & 0,10 & 0,16 & 0,10 \\
\hline$\beta_{\text {supp }, 1}$ & 0,29 & 0,10 & 0,29 & 0,13 & 0,29 & 0,13 \\
\hline$\beta_{\text {supp }, \text { other }}$ & 0,32 & 0,13 & 0,32 & 0,09 & 0,32 & 0,09 \\
\hline
\end{tabular}

Table 7: Estimation Results - Heterogeneity

\begin{tabular}{lccc}
\hline \hline & Regular & Temporary & Cons./Pat. \\
\hline Degree & & & \\
Medical & $62 \%$ & $70 \%$ & $34 \%$ \\
PhD & $35 \%$ & $25 \%$ & $27 \%$ \\
Other degree & $3 \%$ & $5 \%$ & $25 \%$ \\
No Degree & $0 \%$ & $0 \%$ & $14 \%$ \\
& & & \\
Gender & & & \\
Male & $68 \%$ & $69 \%$ & $29 \%$ \\
Female & $32 \%$ & $31 \%$ & $71 \%$ \\
& & & \\
Total & $100 \%$ & $100 \%$ & $100 \%$ \\
Frequency & 2,847 & 1,074 & 377 \\
\hline \hline
\end{tabular}

Table 8: Voter Characteristics by Type for Sequential Voting

\section{Information aggregation}

In this section, we consider whether the switch to simultaneous voting improved the information aggregation in the FDA committees thereby potentially leading to more 
informed drug approval decisions. We first develop a measure of information aggregation that focuses on how closely updated beliefs, after voting has taken place, align with the true state. Distilling on our estimated parameter values we find that simultaneous voting performs slightly better than sequential voting. However, it is important to note that there exist parameter values for which the sequential procedure improves information aggregation. Secondly, we consider how committee votes may translate into drug approval decisions and under which voting procedure more accurate approval decisions are made.

\subsection{Updated beliefs}

We refer to the notion of expected distance (ED) as our measure of information aggregation. This notion captures the difference between the beliefs that a Bayesian updater would have about the state being 1 after observing all the votes (but not the signals), and the true state. A larger discrepancy signifies that updated beliefs are further away from the true state, and hence signifies less accurate information aggregation. Let $v_{N}^{j}$ be a specific sequence of votes with $N$ voters. The set $V^{j}$ comprises of all possible voting sequences with $N$ voters. We denote the updated Bayesian beliefs about the state after $N$ experts have voted by $\mu_{N+1}^{j}\left(v_{N}^{j}\right) \equiv P\left(\theta^{j}=1 \mid v_{N}^{j}\right) . E D_{N}$ is the weighted absolute difference between $\mu_{N+1}^{j}\left(v_{N}^{j}\right)$ and $\theta$ across all possible voting profiles and can be computed analytically:

$$
\begin{aligned}
E D_{N}(\Phi) & =\mu_{0}^{j} \sum_{v^{j} \in V^{j}} \operatorname{Pr}\left(v_{N}^{j} \mid \Phi, \theta=1\right) \times\left(1-\mu_{N+1}^{j}\left(v_{N}^{j}\right)\right) \\
& +\left(1-\mu_{0}^{j}\right) \sum_{v^{j} \in V^{j}} \operatorname{Pr}\left(v_{N}^{j} \mid \Phi, \theta=0\right) \times \mu_{N+1}^{j}\left(v_{N}^{j}\right)
\end{aligned}
$$

Figure 4 shows the $E D$ for $\lambda=0.46, \tau=1.28$, and different values of $\mu_{0}$. The values of $\mu_{0}$ are a selection given the estimated $\beta$ 's. We see that $E D$ is consistently lower for simultaneous voting than sequential voting although the difference is small. While the informational gain of adding more committee members is initially high the $E D$ curve quickly flattens and there is little effect from increasing committee size above 12 members. In Figure 5 we consider a lower value of $\tau(0.8)$ and show that the difference between simultaneous and sequential voting can be quite substantial when $\tau$ is less than 1. This highlights the potential negative effects of herd voting. In the case of a lower $\tau$ we see that adding members to the committee continues to have a significant positive effect even for relatively large committees. 
The results above may not come as a surprise: Herd voting causing informational inefficiencies (learning types being increasingly influenced, or dominated, by the vote history). This is also the conclusion from the herding literature building on a binary signal structure. ${ }^{29}$ Further, the literature studying continuous private signals mainly focuses on asymptotic properties and whether or not erroneous herds or cascades exist. However, in our simple model it is not difficult to find examples where sequential voting does better than simultaneous voting in terms of information aggregation. ${ }^{30}$ We know that the informative type's cutoff strategy depends the common prior and there is no guarantee that this cutoff strategy minimizes $E D$. In the simple case of a one person committee, it can easily be shown that when $\mu_{0} \neq 0.5$ the informative type's cutoff point is different from the cutoff strategy which minimizes $E D_{1}$. It is also worth noting that the cutoff point which minimizes $E D_{1}$ is not necessarily one half. Furthermore, there is no guarantee, all else equal, that the cutoff point of the learning type is more extreme (closer to the boundaries) than the cutoff point of the informative type. For example, if the prior is unbalanced then a countervailing vote drastically changes the cutoff point of subsequent learning types, at least temporarily, who might then become more reliant on their own signal (i.e. voting yes for good signals and no for bad signals) whereas informative types stick to their original cutoff point.

\footnotetext{
${ }^{29}$ An exception is Wiedman (2014) who shows that sequential voting may increase information transmission compared to simultaneous voting in a model with binary signals and competent versus incompetent experts.

${ }^{30}$ For example, when $\mu_{0}=0.75, \tau=2, \lambda=0.8$, and $N=3$.
} 

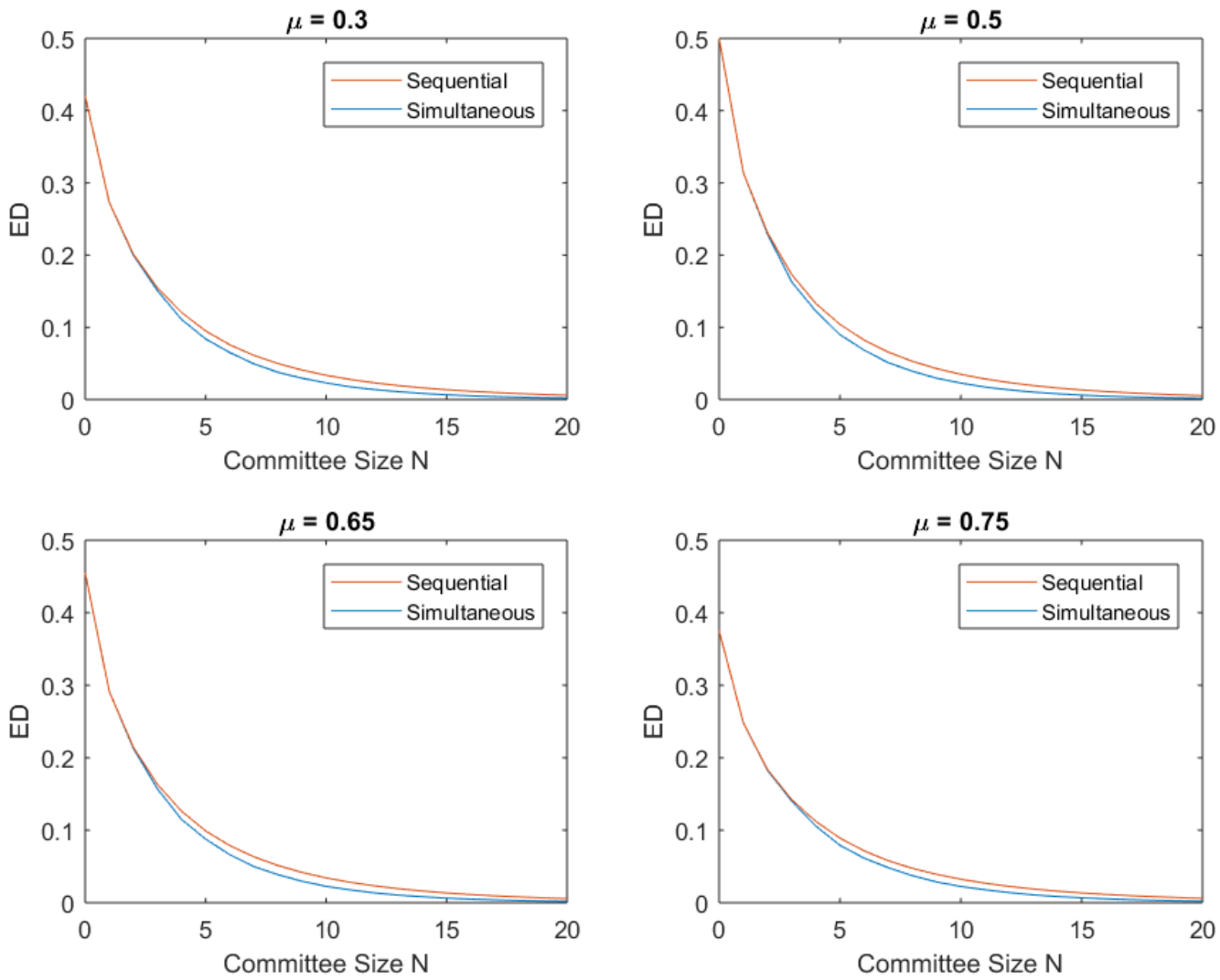

Figure 4: Expected Distance $(\tau=1.28, \lambda=0.46)$ 

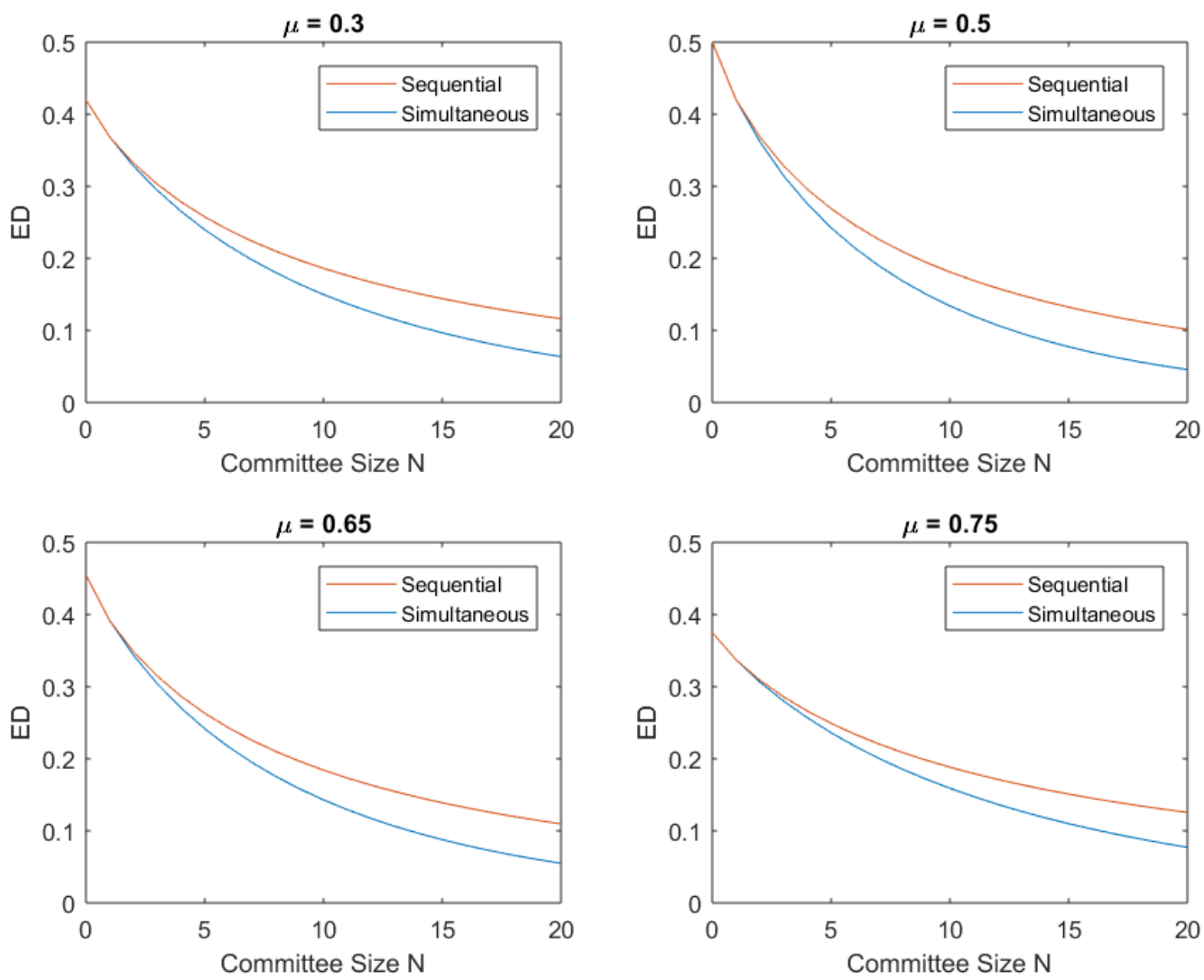

Figure 5: Expected Distance $(\tau=0.8, \lambda=0.46)$

\subsection{Drug approvals}

In this subsection we consider how committee voting could translate into correct (and incorrect) drug approval decisions. It is a difficult task to link voting outcomes to drug approval decisions since it is unclear how the FDA interprets votes and what additional information and follow up data the FDA has access to. We contemplate two distinct FDA decision rules. First, assume that the FDA approves a drug if, and only if, $\mu_{N+1}^{j}\left(v_{N}^{j}\right)>1 / 2$. We call this decision rule $\mu_{N+1}$-majority. That is, the FDA approves if, and only if, the Bayesian beliefs about the state being 1 after all the experts have voted is greater than one half. Second, we consider a simple majority rule where the FDA approves on the matter of question $j$ if the percentage of "yes" votes is greater than 0.5. An important difference between these two decision rules is that the $\mu_{N+1}$-majority rule assumes that the FDA has a sense of the common prior and thus can calculate an updated prior, whereas this is not the case for the simple majority rule. 
Using our simulated dataset of 52,000 votes, where we know what the actual state is, we are able to calculate the probability (for this sample) that the committee makes the correct (or incorrect) decision. ${ }^{31}$ Table 9 shows the percentage of voting questions that fall into each category (correct yes, correct no, incorrect no and incorrect yes) under each voting procedure and decision making rule for a committee of 13 members. Under the $\mu_{N+1}$-majority rule simultaneous voting performs better. Under the simple majority decision rule, given a prior of 0.65 , sequential voting narrowly performs better with a lower probability of making an error overall (3.7\% vs. 2.4\%). As the prior becomes more extreme sequential voting performs increasingly better than simultaneous voting under a simple majority rule. To illustrate this point, suppose the prior is unbalanced, say favoring the yes-state, and voting is simultaneous. In this case, members with a weak "bad" signal vote yes, as it is still more likely that the state is "yes." This makes it unlikely that the majority of the committee votes no even if the state is no, provided that $\tau$ is not too high. However, if voting is sequential then members with a strong "bad" signal can turn the beliefs around and spur subsequent learning types with weak "bad" signals to vote no and thereby cause the majority to favor no.

\begin{tabular}{lccccc}
\hline \hline & \multicolumn{2}{c}{$\mu_{N+1}$-majority } & & \multicolumn{2}{c}{ Simple majority } \\
\cline { 2 - 3 } \cline { 5 - 6 } & Simultaneous & Sequential & & Simultaneous & Sequential \\
\hline Correct yes (approval) & $62.05 \%$ & $61.85 \%$ & & $62.50 \%$ & $61.85 \%$ \\
Correct no (rejection) & $37.05 \%$ & $36.85 \%$ & & $33.80 \%$ & $35.75 \%$ \\
Incorrect yes (type 1) & $0.45 \%$ & $0.65 \%$ & & $3.70 \%$ & $1.75 \%$ \\
Incorrect no (type 2) & $0.45 \%$ & $0.65 \%$ & & $0 \%$ & $0.65 \%$ \\
\hline
\end{tabular}

Table 9: Vote Outcomes $(\tau=1.28, \lambda=0.46, \mu=0.65, N=13)$

To get an idea of how committee voting maps onto drug approvals in reality, we match our dataset of voting questions to data on drug approvals from the FDA Orange Book which provides information on all approved drugs in the U.S. We focus on the questions that relate to risk vs. benefit, since these questions most closely capture the committee's overall stance regarding approval. We exclude biologicals since these products cannot be matched with the FDA Orange Book. This gives us a sample of 263 voting questions (117 under sequential voting and 146 under simultaneous voting). For

\footnotetext{
${ }^{31}$ We are also able to calculate these measures analytically. Analytical and simulated results are virtually identical.
} 
this subset of voting questions, we can see whether the drug in question was actually approved or not.

Interestingly, we find that what the majority of committee members recommends more closely maps into drug approvals under simultaneous voting. Under sequential voting, for $65 \%$ of drugs where the majority of committee members was in favor of the drug, the drug was approved. Under simultaneous voting, this figure is $77 \%$. Under sequential voting, for $60 \%$ of the drugs where the majority was not in favor of the drug or was undecided (3 cases), the drug was not approved. Under simultaneous voting this figure is $66 \%$. These observations square with what we find for the $\mu_{N+1}$-majority rule: Using our simulated dataset, we find that if drug approval decisions are made by the $\mu_{N+1}$-majority rule, then there will be a greater alignment of approvals (or rejections) with the majority of votes under simultaneous voting than sequential voting. Hence, there is some evidence suggesting that a decision rule like the $\mu_{N+1}$-majority rule is in place; for which simultaneous voting outperforms sequential voting.

\section{Conclusion}

In this paper we use data from the FDA's advisory committees to structurally estimate a voting model which allows us to assess the proportion of expert members who are susceptible to herd behavior. We utilize a novel data set with information on the full voting profiles for sequential and simultaneous polling. Our main finding is that under sequential voting almost half of the committee members take the preceding votes into consideration when aiming for the correct answer to the voting question. We also report variation in the proportion of learning types across different member characteristics e.g. temporary committee members are more apt to herding than regular (standing) members. We believe that our results and analysis are relevant beyond medical expert committees: In situations where people are assembled to provide their professional advice or vote on specific questions, from corporate supervisory boards to expert hearings and city councils or parliaments voting on ideology neutral matters.

In future work we intent to explore the mechanisms behind our main findings and take a closer look at different member characteristics and follow the same individuals across different voting questions. To this end, diving into the comments and pre-vote discussions from the FDA meeting transcripts using sentiment analysis and text mining could be fruitful. Another array of future research that we plan to take is to study the 
FDA's decision making process, taking into account the advisory committee votes, and the quality of drug approval decisions. The quality of the FDA decisions can be approximated by e.g. considering drug withdrawals or decisions made by other agencies like the European Medicines Agency. Finally, we plan to further examine how the FDA experts update their beliefs upon observing the preceding votes. This includes testing distinct theories, departing from pure Bayesian updating, that have so far only been examined in controlled laboratory experiments.

\section{References}

Ackerley, N., Eyraud, J., Franz, C., Kissel, B., and Metivier, D. (2009). Financial conflict-of-interest disclosure and voting patterns at fda advisory committee meetings. Washington, DC: Eastern Research Group.

Ali, N., Goeree, J. K., Kartik, N., and Palfrey, T. R. (2008). Information aggregation in standing and ad hoc committees. American Economic Review, 98(2):181-186.

Allman, E. S., Matias, C., and Rhodes, J. A. (2009). Identifiability of parameters in latent structure models with many observed variables. The Annals of Statistics, pages 3099-3132.

Anderson, L. R. and Holt, C. A. (1997). Information cascades in the laboratory. American Economic Review, pages 847-862.

Angrisani, M., Guarino, A., Jehiel, P., and Kitagawa, T. (2017). Information redundancy neglect versus overconfidence: a social learning experiment. Cemmap Working Paper.

Asch, S. E. (1951). Effects of group pressure upon the modification and distortion of judgments. In Guetzkow, H., editor, Groups, leadership, and men, pages 222-236. Carnegie Press, Pittsburgh.

Banerjee, A. V. (1992). A simple model of herd behavior. Quarterly Journal of Economics, 107(3):797-817.

Bernheim, D. B. and Exley, C. L. (2015). Understanding conformity: An experimental investigation. Harvard Business School Working Papers. 
Bikhchandani, S., Hirshleifer, D., and Welch, I. (1992). A theory of fads, fashion, custom, and cultural change as informational cascades. Journal of Political Economy, 100(5):992-1026.

Brennan, G. and Hamlin, A. (1998). Expressive voting and electoral equilibrium. Public Choice, 95(1-2):149-175.

Brennan, G. and Pettit, P. (2000). The hidden economy of esteem. Economics and Philosophy, 16:77-98.

Cai, H., Chen, Y., and Fang, H. (2009). Observational learning: Evidence from a randomized natural field experiment. American Economic Review, 99(3):864-82.

Callander, S. (2007). Bandwagons and momentum in sequential voting. Review of Economic Studies, 74(3):653-684.

Camara, F. and Dupuis, N. (2014). Structural estimation of expert strategic bias: the case of movie reviewers. Working paper.

Camara, F. and Kyle, M. (2016). Experts and financial ties: Evidence from fda advisory committees. Working paper.

Çelen, B. and Kariv, S. (2004). Distinguishing informational cascades from herd behavior in the laboratory. American Economic Review, 94(3):484-498.

Cipriani, M. and Guarino, A. (2014). Estimating a structural model of herd behavior in financial markets. American Economic Review, 104(1):224-251.

Cooper, J. C. and Golec, J. (2017). Conflicts of interest on expert committees: The case of fda drug advisory committees. Working paper.

Dekel, E. and Piccione, M. (2000). Sequential voting procedures in symmetric binary elections. Journal of Political Economy, 108(1):34-55.

Deutsch, M. and Gerard, H. B. (1955). A study of normative and informational social influences upon individual judgment. Journal of Abnormal and Social Psychology, $51(3): 629$.

Duggan, J. and Martinelli, C. (2001). A bayesian model of voting in juries. Games and Economic Behavior, 37(2):259-294. 
Eagly, A. H. and Carli, L. L. (1981). Sex of researchers and sex-typed communications as determinants of sex differences in influenceability: a meta-analysis of social influence studies. Psychological Bulletin, 90(1):1.

Eyster, E. and Rabin, M. (2010). Naive herding in rich-information settings. American economic journal: microeconomics, 2(4):221-43.

Gerardi, D. and Yariv, L. (2008). Information acquisition in committees. Games and Economic Behavior, 62(2):436-459.

Gerling, K., Grüner, H. P., Kiel, A., and Schulte, E. (2005). Information acquisition and decision making in committees: A survey. European Journal of Political Economy, 21(3):563-597.

Graham, D. J., Campen, D., Hui, R., Spence, M., Cheetham, C., Levy, G., Shoor, S., and Ray, W. A. (2005). Risk of acute myocardial infarction and sudden cardiac death in patients treated with cyclo-oxygenase 2 selective and non-selective non-steroidal anti-inflammatory drugs: nested case-control study. The Lancet, 365(9458):475-481.

Graham, J. R. (1999). Herding among investment newsletters: Theory and evidence. Journal of Finance, 54(1):237-268.

Iaryczower, M. and Shum, M. (2012). The value of information in the court: Get it right, keep it tight. American Economic Review, 102(1):202-37.

Knight, B. and Schiff, N. (2010). Momentum and social learning in presidential primaries. Journal of Political Economy, 118(6):1110-1150.

Li, H. and Suen, W. (2009). Decision-making in committees. Canadian Journal of Economics/Revue canadienne d'économique, 42(2):359-392.

Lurie, P. and Zieve, A. (2006). Sometimes the silence can be like the thunder: access to pharmaceutical data at the fda. Law and Contemporary Problems, 69(3):85-97.

McKelvey, W. and Kerr, N. H. (1988). Differences in conformity among friends and strangers. Psychological Reports, 62(3):759-762.

Meade, E. (2005). The fomc: Preferences, voting, and consensus. Federal Reserve Bank of St. Louis Review, 87(2):93-101.

Moffitt, S. L. (2010). Promoting agency reputation through public advice: Advisory committee use in the fda. The Journal of Politics, 72(3):880-893. 
Ottaviani, M. and Sørensen, P. (2001). Information aggregation in debate: who should speak first? Journal of Public Economics, 81(3):393-421.

Shiller, R. J. (1995). Conversation, information, and herd behavior. American Economic Review, 85(2):181-185.

Smith, L. and Sørensen, P. (2000). Pathological outcomes of observational learning. Econometrica, 68(2):371-398.

Weizsäcker, G. (2010). Do we follow others when we should? a simple test of rational expectations. American Economic Review, 100(5):2340-60.

Welch, I. (1992). Sequential sales, learning, and cascades. Journal of Finance, 47(2):695-732.

Wiedman, E. (2014). Good information cascades. Working paper. 


\section{Appendix A: Seating order}

In this appendix we present descriptive statistics concerning seating order under sequential voting. In Table A2 we split the sample of votes by voter characteristics and calculate summary statistics on seat number for each category. Based on these statistics it is clear that different types of committee members, e.g. those with a $\mathrm{PhD}$ or male committee members, are very spread out in terms of where they sit in the sequence. The average seat position for all groups is around 7 with a standard deviation of around 4.5. There are no clear clusters of certain types of committee members at start or end of the voting sequence.

In Figure A1 we present a more visual depiction of how regular committee members are spread over different seat numbers. For each seat number, we calculate the percentage of times a regular committee member votes in this seat number using the sample of all sequential votes. We plot the percentage of regular members by seat number and the frequency of each seat number under sequential voting. If we focus on the more frequent seat numbers, the percentage of times a regular committee member votes in a given seat is fairly stable and there is no clear trend.

Finally, we show that even individual committee members are spread out in terms of where they sit and do not always get placed in the same seat number. Based on the name of the committee member we can determine how often each committee member has participated in a vote under sequential voting. We focus on the 10 most frequent voters and provide summary statistics concerning their seating position in Table A2.

\begin{tabular}{lccccc}
\hline \hline Voter Characteristic & Frequency & Mean Seat & Std. dev. & Min & Max \\
\hline Regular & 2847 & 6.80 & 4.38 & 1 & 28 \\
Consumer patient rep. & 377 & 6.99 & 4.42 & 1 & 23 \\
PhD & 1352 & 6.37 & 4.10 & 1 & 25 \\
Medical & 2579 & 7.02 & 4.63 & 1 & 28 \\
Other degree & 266 & 7.32 & 4.64 & 1 & 26 \\
No degree & 101 & 7.83 & 5.01 & 1 & 21 \\
Male & 2782 & 6.63 & 4.47 & 1 & 28 \\
All Sequential Votes & 4298 & 6.85 & 4.50 & 1 & 28 \\
\hline \hline
\end{tabular}

Table A1: Summary statistics for seat no. by voter characteristics 


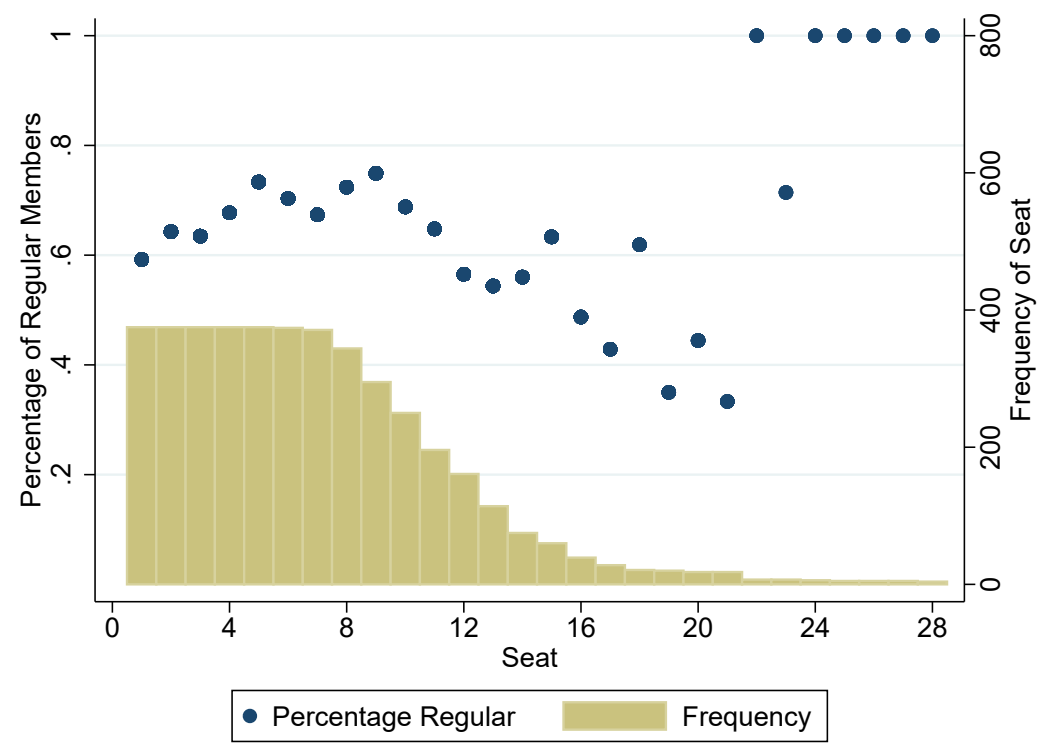

Figure A1: Percentage of regular members by seat no. and frequency of seat no.

\begin{tabular}{lccccc}
\hline \hline Voter ID & Frequency & Mean Seat & Std. dev. & Min & Max \\
\hline 570 & 62 & 5.10 & 2.29 & 1 & 11 \\
985 & 46 & 8.91 & 3.44 & 2 & 15 \\
1284 & 46 & 5.67 & 3.10 & 1 & 11 \\
539 & 44 & 5.93 & 3.01 & 1 & 11 \\
1141 & 43 & 7.28 & 5.01 & 1 & 18 \\
1051 & 42 & 5.79 & 3.90 & 1 & 14 \\
791 & 40 & 6.00 & 3.75 & 2 & 15 \\
813 & 40 & 7.30 & 2.74 & 3 & 13 \\
981 & 40 & 6.95 & 4.01 & 2 & 17 \\
848 & 38 & 4.87 & 3.08 & 1 & 11 \\
\hline \hline
\end{tabular}

Table A2: Summary statistics for seat no. for 10 most frequent voters 


\section{Appendix B: Correlations in vote questions part of the same meeting}

In our empirical implementation, we assume that there is an underlying (latent) variable

$y_{j}^{*}$ that determines the true state for a voting question j. We specify $y_{j}^{*}=X_{j}^{\prime} \beta+\epsilon_{j}$ such that:

$$
\theta^{j}= \begin{cases}1 & \text { for } y_{j}^{*}>0 \\ 0 & \text { for } y_{j}^{*} \leq 0\end{cases}
$$

We further assume $\epsilon_{j}$ has a standard logistic distribution which implies $\operatorname{Pr}\left(\theta^{j}=\right.$ $1 \mid X)=\frac{\exp \left(X_{j}^{\prime} \beta\right)}{1+\exp \left(X_{j}^{\prime} \beta\right)}$.

Given that we can have multiple voting questions taking place on the same day and relating to the same drug (on average 2-3 voting questions per meeting), we may expect correlation in the true state across voting questions that are part of the same meeting.

We can allow for such correlation by introducing an error term at the meeting level $\epsilon_{m}$. We now specify the underlying (latent) variable as $y_{j}^{*}=X_{j}^{\prime} \beta+\left((1-\sigma) \epsilon_{j}+\sigma \epsilon_{m}\right)$. If $\sigma$ is 0 this collapses to the previous specification, as $\sigma$ increases there is more correlation in the true state for voting questions that are part of the same meeting. Given that private signals are state dependent, there will also be more correlation in private signals within a meeting. Assuming $\epsilon_{m}$ follows the standard logistic distribution, the new error term $\left((1-\sigma) \epsilon_{j}+\sigma \epsilon_{m}\right)$ also follows the standard logistic distribution. Hence we still have $\operatorname{Pr}\left(\theta^{j}=1 \mid X\right)=\frac{\exp \left(X_{j}^{\prime} \beta\right)}{1+\exp \left(X_{j}^{\prime} \beta\right)}$.

In our simulations we implement such an error structure by grouping questions into sets of four and drawing the same $\epsilon_{m}$ for the set. We use a $\sigma$ of 0.7. We find that our estimates of $\beta, \lambda$, and $\tau$ are unbiased and very similar to what they were before introducing the correlation. 
Appendix C: Alternative specification of the prior

In order to illustrate the robustness of our results to different specifications of the prior, we implement a model where we estimate a prior for each committee meeting i.e. we estimate 327 priors corresponding to the 327 committee meetings in our dataset. In order to ease estimation of a model with so many parameters, we use constrained minimization (fmincon in Matlab). We constrain $\lambda$ and all elements in the vector of common priors $\mu_{0}$ to be between 0 and 1 . We constrain $\tau$ to be between 0 and 5 .

Table C1 provides the parameter estimates of this model. We do not report all 327 estimated priors, rather we summarize our estimates in Table C2. As we might expect, introducing meeting level fixed effects allows the prior to vary much more across voting questions and so reduces our estimates of $\tau$ and $\lambda$, but not by too much. We now find that on average $31 \%$ of committee members are learning types. Using a simulated dataset, we find that $19 \%$ of learning types herd, hence overall almost $7 \%$ of votes are herd votes.

\begin{tabular}{lcc}
\hline \hline Parameter & Estimate & SD \\
\hline$\tau$ & 1,15 & 0,04 \\
$\lambda$ & 0,31 & 0,05 \\
\hline \hline
\end{tabular}

Table C1: Estimation Results

\begin{tabular}{lcccccc}
\hline \hline & & & & \multicolumn{2}{c}{ Mean by Voting Rule } \\
\cline { 6 - 7 } Parameter & Number of estimates & Mean & Max & Min & Sequential & Simultaneous \\
\hline$\mu_{0}$ & 327 & 0,61 & 1 & 0,03 & 0,62 & 0,6 \\
SD $\left(\mu_{0}\right)$ & 327 & 0,12 & 0,24 & 0,03 & 0,14 & 0,11 \\
\hline \hline
\end{tabular}

Table C2: Estimation Results $-\mu_{0}$ 


\section{Appendix D: Naive herding}

In this appendix, we estimate our model under the assumption that learning types are "naive" learners. Naive learners (incorrectly) believe that each previous person's action reflects solely that person's private information (see Eyster and Rabin (2010)). In our model this translates into learning types believing that everyone before them is an informative type. This assumption requires an adjustment to the way we calculate the updated prior. We denote the updated prior under the assumption of naive learning as $\mu_{N, i}^{j}$.

$$
\mu_{N, i}^{j} \equiv P\left(\theta^{j}=1 \mid h_{i}^{j}\right)=\frac{\mu_{N, i-1}^{j} P_{N, 1, i-1}^{v_{i-1}}\left(1-P_{N, 1, i-1}\right)^{1-v_{i-1}}}{\mu_{N, i-1}^{j} P_{N, 1, i-1}^{v_{i}-1}\left(1-P_{N, 1, i-1}\right)^{1-v_{i-1}}+\left(1-\mu_{N, i-1}^{j}\right) P_{N, 0, i-1}^{v_{i}-1}\left(1-P_{N, 0, i-1}\right)^{1-v_{i-1}}}
$$

where,

$$
\begin{aligned}
& P_{N, 1, i} \equiv P\left(v_{i}^{j}=1 \mid \Phi, h_{i}^{j}, \theta=1\right)=P\left(s_{i}^{j}>\bar{s}_{i, t=I}^{j} \mid \Phi, \theta=1\right) \\
& P_{N, 0, i} \equiv P\left(v_{i}^{j}=1 \mid \Phi, h_{i}^{j}, \theta=0\right)=P\left(s_{i}^{j}>\bar{s}_{i, t=I}^{j} \mid \Phi, \theta=0\right)
\end{aligned}
$$

Table D1 presents the results.

\begin{tabular}{lcc}
\hline \hline Parameter & Estimate & $\mathrm{SD}$ \\
\hline$\tau$ & 1,28 & 0,03 \\
$\lambda$ & 0,52 & 0,04 \\
$\beta_{\text {nonsupp },-1}$ & $-0,18$ & 0,10 \\
$\beta_{\text {nonsupp }, 0}$ & 0,20 & 0,05 \\
$\beta_{\text {nonsupp }, 1}$ & 1,03 & 0,08 \\
$\beta_{\text {nonsupp }, \text { other }}$ & 0,25 & 0,05 \\
$\beta_{\text {supp },-1}$ & $-0,50$ & 0,19 \\
$\beta_{\text {supp }, 0}$ & 0,15 & 0,09 \\
$\beta_{\text {supp }, 1}$ & 0,28 & 0,13 \\
$\beta_{\text {supp }, \text { other }}$ & 0,34 & 0,09 \\
\hline \hline
\end{tabular}

Table D1: Estimation Results - Naive herding 